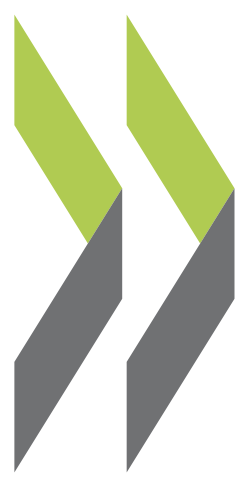

SIGMA Papers No. 53

Functioning of the Centres of Government in the Western Balkans

Péter Vági,

Keit Kasemets 


\title{
Functioning of the Centres of Government in the Western Balkans
}

\author{
SIGMA PAPER No. 53
}

Authorised for publication by Karen Hill, Head of the SIGMA Programme 


\section{Table of Contents}

Foreword

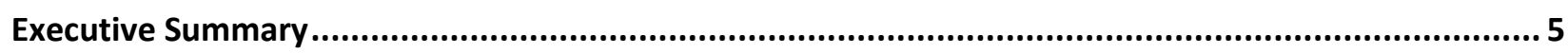

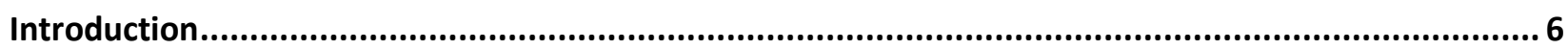

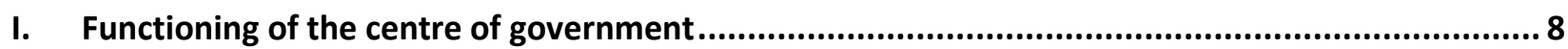

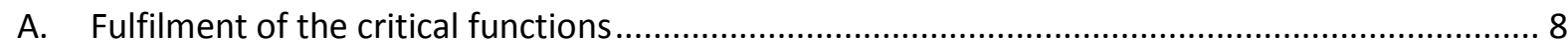

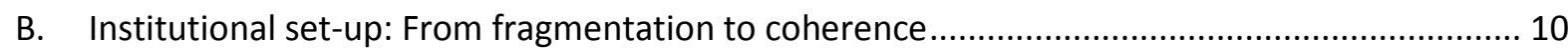

II. Preparing government decisions and ensuring conformity of the decisions.............................. 17

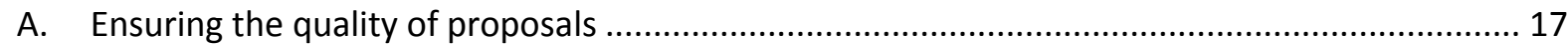

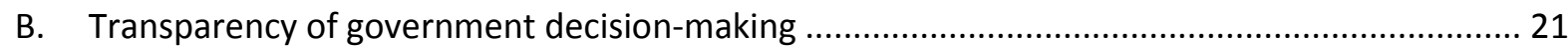

III. Planning medium-term policies and sector strategies.............................................................. 23

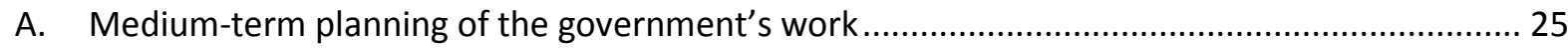

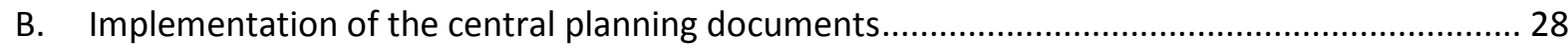

C. Development and implementation of sector policies .............................................................. 31

IV. Regular monitoring of government performance …..................................................................... 36

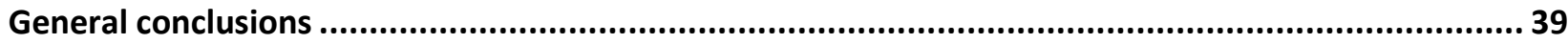

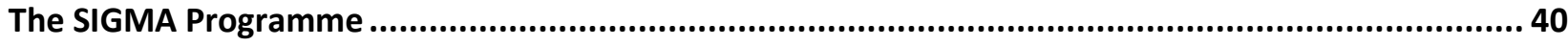




\section{Foreword}

A well-functioning policy-making system is a key pillar of a transparent and effective democratic system. It is also a crucial precondition for the country to make progress in the European integration (EI) process as the capacity of national administrations to undertake the obligations linked with European Union (EU) membership is a key criterion in the assessment of candidate preparedness.

The institutional architecture at the centre of government (CoG) for carrying out policy-planning and co-ordination functions should be in place and able to ensure the well-organised and competent functioning of the policy-making system. The CoG is defined through the key functions typically carried out by the Government Office/General Secretariat, the Ministry of Finance (MoF), the body responsible for legal conformity and the body responsible for El when fulfilling the policy-planning, co-ordination and development functions. The institutional set-up within and between those institutions should be without significant gaps and overlaps, and should not be overly fragmented. The CoG should have the authority and capacity to perform the tasks related to overall management of the policy system. It also should have actual capacity and authority to implement and enforce the provisions of the legal framework.

The policy and legislative outcomes of the government should be planned in keeping with the capacity of the administration and financial circumstances of the government, be coherent, focus on priorities, and ensure that the government performs collectively and keeps its promises to the public. The government should regularly oversee the existing legislative framework to ensure that it remains relevant and up-todate.

In order to ensure transparent and legally compliant decision making, the CoG should have the capacity to perform the tasks related to the overall management of government decision making, as well as the actual capacity and authority (legal, personal and professional) to implement and enforce the provisions of the legal framework, and ensure a transparent, reliable and legal process.

This paper provides a comparative analysis of the functioning of the CoG in the Western Balkans. The analysis concentrates on the functioning of the key CoG institution (usually the Office of the Prime Minister [OPM] or similar ${ }^{1}$ ), but also covers the functioning of other institutions implementing some of the CoG roles (like the MoF or the institutions dealing with EI), depending on the institutional set-up and distribution of functions in different countries. The analysis starts out from the Principles of Public Administration for EU accession countries, developed by SIGMA in co-operation with the European Commission ${ }^{2}$, and builds on the Baseline Measurement Reports ${ }^{3}$ prepared by SIGMA in 2015 . The Principles define nine critical functions, to be implemented by the CoG, that are necessary for a well-organised, consistent and competent policy-making system. These are:

- co-ordination of preparation of the government sessions;

- ensuring legal conformity;

- co-ordination of preparation and approval of the government's strategic priorities and work programme;

- co-ordination of the policy content of proposals for government decision making, including defining the policy preparation process and ensuring coherence with government priorities;

- ensuring that policies are affordable and co-ordination of public sector resource planning;

- co-ordination of the government's communication activities to ensure a coherent government message;

This Paper does not include analysis of the role of the cabinets of the Prime Minister and covers only the functioning of the CoG fulfilled by civil servants.

SIGMA (2014), The Principles of Public Administration, OECD Publishing, Paris.

SIGMA (2015), Baseline Measurement Reports, OECD Publishing, Paris. 
- monitoring of the government's performance to ensure the government collectively performs effectively and keeps its promises to the public;

- handling relations between the government and other parts of the state (president, parliament);

- co-ordination of El affairs.

The analysis takes stock of the organisational set-up, regulatory framework and the practices of these key functions in the Western Balkans, highlighting similarities and differences, and also gives examples from some EU Member States.

The development of this paper was led by Péter Vági of the SIGMA Programme and by Keit Kasemets from the Estonian Ministry of Economic Affairs and Communication, with substantial expert contribution from João Freire from the Portuguese Ministry of Justice. The team would also like to thank Jolanda Trebicka, Amir Ćesić, Neda Maleska, Martin Todevski, Jovana Marović, Milena Lazarevic and Sena Marić who assisted with the data collection for this analysis. 


\section{Executive Summary}

The approach of the Western Balkan governments to the set-up of the CoG varies. Some, such as Albania, concentrate most of the critical CoG functions in one institution, such as the OPM. In other countries the functions are allocated to several institutions, as is done in Serbia, where in addition to the General Secretariat of the Government, several key functions are fulfilled by the Public Policy Secretariat of the Republic of Serbia (PPS) and there is also a separate institution for ensuring legal conformity. None of the approaches is unique to the Western Balkans, since the EU and OECD countries also use different models.

However, it is crucial to fulfil all critical functions, irrespective of the institutional set-up, and to ensure that there is clarity on the distribution of functions, smooth co-operation between various units, and proper allocation of resources for fulfilling the functions. In general, the legal framework for the establishment and operations of all critical CoG functions is in place, as are routines ensuring the basic functioning of the system in all Western Balkan governments. All centres of government have well-established structures for preparing government sessions and ensuring legal conformity of government decisions. The centres of government have different mandates for fulfilling these duties in the different Western Balkan governments, and this also influences the general approach to the role of the CoG. In those countries where the CoG's mandate is more limited, the role of the CoG is more technical and the overall policy-planning and co-ordination system is more fragmented. In countries with a stronger CoG, the institution usually also has a greater say on policy planning and co-ordination, and its role is more central in ensuring a "gate-keeping" function to lead to better-designed policy decisions by the government.

Nevertheless, key challenges for CoG institutions across the Western Balkans consist of improving their performance in planning the work of the government, analysing policy content, and monitoring the government's performance. This involves:

- streamlining the medium-planning system, in particular increasing coherence in the central planning of the government's work and decreasing implementation backlog ${ }^{4}$ through more realistic planning and processes for improved implementation;

- creation of linkages between planning and financial affordability of policies, in particular improving costing of policies and aligning financial and policy planning;

- consolidation of the sector policy planning through improving the planning framework, decreasing fragmentation of the sector strategies and increasing the quality of strategy development;

- strengthening of the monitoring of the government's performance through creating a more coherent framework, moving towards monitoring the outcomes of the work and increasing transparency of the system.

Increasing the capacities of the CoG, improving co-operation both between and within the CoG institutions, and taking a more active role in developing the policy planning and co-ordination system will enable the CoG to overcome these challenges and improve the system.

In the following analysis the phrase "implementation backlog" is used interchangeably with the meaning of the proportion of items carried forward from one year's plan to the following year. For more information on the calculation of the backlog: SIGMA (2015), Baseline Measurement Reports, OECD Publishing, Paris, p. 9. 


\section{Introduction}

The functioning of the CoG is crucial to how well the whole policy co-ordination and policy-development system operates and how the government can deliver its objectives in a given country. Governance systems depart from distinct political and administrative cultures, and therefore both the functions and the set-ups of the centres of government vary. However, there are some critical functions on which the CoG institutions need to deliver, regardless of these variances. These functions are defined in the Principles of Public Administration for accession countries developed by SIGMA ${ }^{5}$. The key CoG institution is the Government Office (often named as the Prime Minister's Office or the General Secretariat in the Western Balkans). However, in most countries, critical CoG functions are also fulfilled by other institutions, such as the MoF, the Legal Secretariat or Ministry of Justice (MoJ) and a separate body responsible for $\mathrm{El}$, either as a ministry or in other forms.

Table 1. Institutions fulfilling the centre of government functions in the Western Balkans

\begin{tabular}{|c|c|c|}
\hline Country & $\begin{array}{l}\text { Key centre of government } \\
\text { institution }\end{array}$ & $\begin{array}{l}\text { Other institutions fulfilling centre of } \\
\text { government functions }\end{array}$ \\
\hline Albania & The Office of the Prime Minister & $\begin{array}{l}\text { The Ministry of Finance, the Ministry of } \\
\text { Justice, the Ministry of European Integration } \\
\text { (MEI) }\end{array}$ \\
\hline $\begin{array}{l}\text { Bosnia and } \\
\text { Herzegovina }^{6}\end{array}$ & $\begin{array}{l}\text { The Secretariat General of the } \\
\text { Council of Ministers }\end{array}$ & $\begin{array}{l}\text { The Legislative Office, the Directorate for } \\
\text { Economic Planning, the Ministry of Finance } \\
\text { and Treasury, the Directorate for European } \\
\text { Integration }\end{array}$ \\
\hline Kosovo $^{7}$ & The Office of the Prime Minister & $\begin{array}{l}\text { The Ministry of Finance, the Ministry of } \\
\text { European Integration }\end{array}$ \\
\hline $\begin{array}{l}\text { The former Yugoslav } \\
\text { Republic of Macedonia }\end{array}$ & The General Secretariat & $\begin{array}{l}\text { The Secretariat for Legislation, the Ministry of } \\
\text { Finance, the Secretariat for European Affairs, } \\
\text { the Ministry of Information Society and } \\
\text { Administration (MISA) }\end{array}$ \\
\hline Montenegro & The General Secretariat & $\begin{array}{l}\text { The Secretariat for Legislation, the Ministry of } \\
\text { Finance, the Ministry of Foreign Affairs and } \\
\text { European Integration }{ }^{8}\end{array}$ \\
\hline Serbia & $\begin{array}{l}\text { The General Secretariat of the } \\
\text { Government }\end{array}$ & $\begin{array}{l}\text { The PPS, the Secretariat for Legislation, the } \\
\text { Ministry of Finance, the Serbian European } \\
\text { Integration Office (SEIO) }\end{array}$ \\
\hline
\end{tabular}

Source: SIGMA (2015), Baseline Measurement Reports, OECD Publishing, Paris.

SIGMA (2014), The Principles of Public Administration, OECD Publishing, Paris, p. 21.

Similarly to the SIGMA baseline measurement 2015, this analysis focuses on the state level institutions of Bosnia and Herzegovina, in particular the CoG body (the Secretariat General of the Council of Ministers). The state level often lacks a constitutional mandate to ensure that decision making is co-ordinated throughout the entire country.

$7 \quad$ This designation is without prejudice to positions on status, and is in line with United Nations Security Council Resolution 1244/99 and the Advisory Opinion of the International Court of Justice on Kosovo's declaration of independence.

8 In November 2016 the Montenegro Government decided to create a separate Ministry of European Affairs, by dividing the former Ministry of Foreign Affairs into two (functionally and also organisationally). Both ministries have separate ministers and leadership. 
The paper provides a brief overview on how all critical CoG functions are fulfilled, but concentrates mainly on the functioning of the Government Office/OPMs in the Western Balkans and the implementation of key functions fulfilled by these institutions: medium-term policy planning aligned with financial circumstances; monitoring of the government's performance; preparation of government decisions and ensuring legal conformity.

For the above-mentioned functions, the organisational set-up and delivery capacities of the Western Balkan governments are analysed and practices from EU countries are highlighted. Also, a comparative overview is provided, based on the monitoring framework of the Principles of Public Administration ${ }^{9}$. The starting point of the paper is a comparative analysis of Baseline Measurement Reports prepared by SIGMA in $2015^{10}$. However, in order to properly assess the state of play, the main developments with regards to the functioning of the centres of government in all six Western Balkan governments were examined. Updated information has been gathered from key documents and data since the completion of SIGMA's baseline measurement in May 2015.

In the following chapters, the comparison of the Western Balkan economies will be presented first in terms of the overview of the CoG functions. The preparation of government decisions, including how to ensure the best quality of those decisions, will then be examined, followed by analysis of the medium-term policy planning systems and the monitoring of the government's performance. The paper will end with some general conclusions derived from the comparative analysis.

For a detailed description of the analysis, please see the Methodological Annex to the Indicators, in SIGMA (2015), Baseline Measurement Reports, OECD Publishing, Paris. 


\section{Functioning of the centre of government}

\section{A. Fulfilment of the critical functions}

In general, the legal framework for establishing the critical functions is in place and the routines ensuring the basic functioning of the system are well-established in the Western Balkans. The only exception is Bosnia and Herzegovina, which allocates policy development and co-ordination functions to the State level, the Entities and the Brčko District, often without any co-ordination at the national level.

The maturity of the system can be measured by analysing the formal establishment and actual functioning of nine critical CoG functions. Three functions-preparing government sessions, ensuring legal conformity and co-ordinating EI-are formally established and fully functional in all the Western Balkan governments. The primary challenges relate to the actual implementation of the functions that require well-developed capacities and good inter-institutional co-operation. One example of limited functioning concerns the co-ordination of policy content, where the function is partly established in Bosnia and Herzegovina, not clearly established in Serbia, and not fully functional in the remaining four Western Balkans governments. In Montenegro, there are shortcomings in implementation of the co-ordination of the preparation and approval of government priorities and work programmes, while in Albania the implementation is only partial, as the current good practice is not embedded in a systematic way. For each of the other functions, there is always at least one country that falls short of full implementation. 
Table 2. Fulfilment of the centre of government functions (as of 31 December 2015) ${ }^{11}$

\begin{tabular}{|c|c|c|c|c|c|c|c|c|c|c|c|c|}
\hline & \multicolumn{2}{|c|}{ ALB } & \multicolumn{2}{|c|}{ BIH } & \multicolumn{2}{|c|}{ XKV } & \multicolumn{2}{|c|}{ MKD } & \multicolumn{2}{|c|}{ MNE } & \multicolumn{2}{|c|}{ SRB } \\
\hline General value & \multicolumn{2}{|c|}{4} & \multicolumn{2}{|c|}{2} & \multicolumn{2}{|c|}{4} & \multicolumn{2}{|c|}{4} & \multicolumn{2}{|c|}{4} & \multicolumn{2}{|c|}{4} \\
\hline & Established & Functional & Established & Functional & Established & Functional & Established & Functional & Established & Functional & Established & Functional \\
\hline $\begin{array}{l}\text { Co-ordination of preparation of } \\
\text { the government sessions }\end{array}$ & yes & yes & yes & yes & yes & yes & yes & yes & yes & yes & yes & yes \\
\hline Ensuring legal conformity & yes & yes & yes & yes & yes & yes & yes & yes & yes & yes & yes & yes \\
\hline $\begin{array}{l}\text { Co-ordination of the policy } \\
\text { content of proposals for } \\
\text { government decision-making }\end{array}$ & yes & no & pa* & no & yes & no & no & no & yes & no & pa* & no \\
\hline $\begin{array}{l}\text { Ensuring that policies are } \\
\text { affordable and co-ordination of } \\
\text { public sector resource planning }\end{array}$ & yes & yes & yes & no & yes & yes & yes & yes & yes & yes & yes & yes \\
\hline $\begin{array}{l}\text { Co-ordination of the } \\
\text { government's communication } \\
\text { activities to ensure a coherent } \\
\text { government message }\end{array}$ & yes & yes & yes & $\mathrm{no}^{* *}$ & yes & yes & yes & yes & yes & yes & yes & no $^{* *}$ \\
\hline $\begin{array}{l}\text { Monitoring of the government's } \\
\text { performance }\end{array}$ & yes & yes & yes & yes & yes & yes & yes & yes & yes & yes & yes & yes \\
\hline $\begin{array}{l}\text { Handling relations between the } \\
\text { government and the parliament }\end{array}$ & yes & yes & yes & $\mathrm{no}^{* *}$ & yes & yes & yes & yes & yes & yes & yes & yes \\
\hline $\begin{array}{l}\text { Co-ordination of European } \\
\text { integration affairs }\end{array}$ & yes & yes & yes & yes & yes & yes & yes & yes & yes & yes & yes & yes \\
\hline
\end{tabular}

pa* means "partially"

no "means "no data was provided"

Source: SIGMA (2015), Baseline Measurement Reports, OECD Publishing, Paris. Documents and data provided by the administrations in June-September 2016.

11 For a more detailed description of the scales from 0 to 5, please see the Methodological Annex to the Indicators, in SIGMA (2015), Baseline Measurement Reports, OECD Publishing Paris, p. 8. 


\section{B. Institutional set-up: From fragmentation to coherence}

Despite a broadly similar level of maturity of the centres of government, each country has specificities in its institutional set-up, as well as having a mix of stronger and weaker components in the system. In general terms, two distinct models can be identified: first, the model represented by Albania and Kosovo, where most of the functions are concentrated in the OPM. Only two key tasks remain in other ministries: the MoF takes care of ensuring financial affordability of the policies and the MEI manages EU affairs. This model is typical for several EU and OECD countries that have a strong Cabinet Office or Chancellery, such as the United Kingdom, Finland, Sweden, Hungary and Estonia. In the case of Finland, EU issues are also handled by the OPM, as they are in Estonia and Hungary.

Figure 1. Organisational chart of the Finnish Office of the Prime Minister

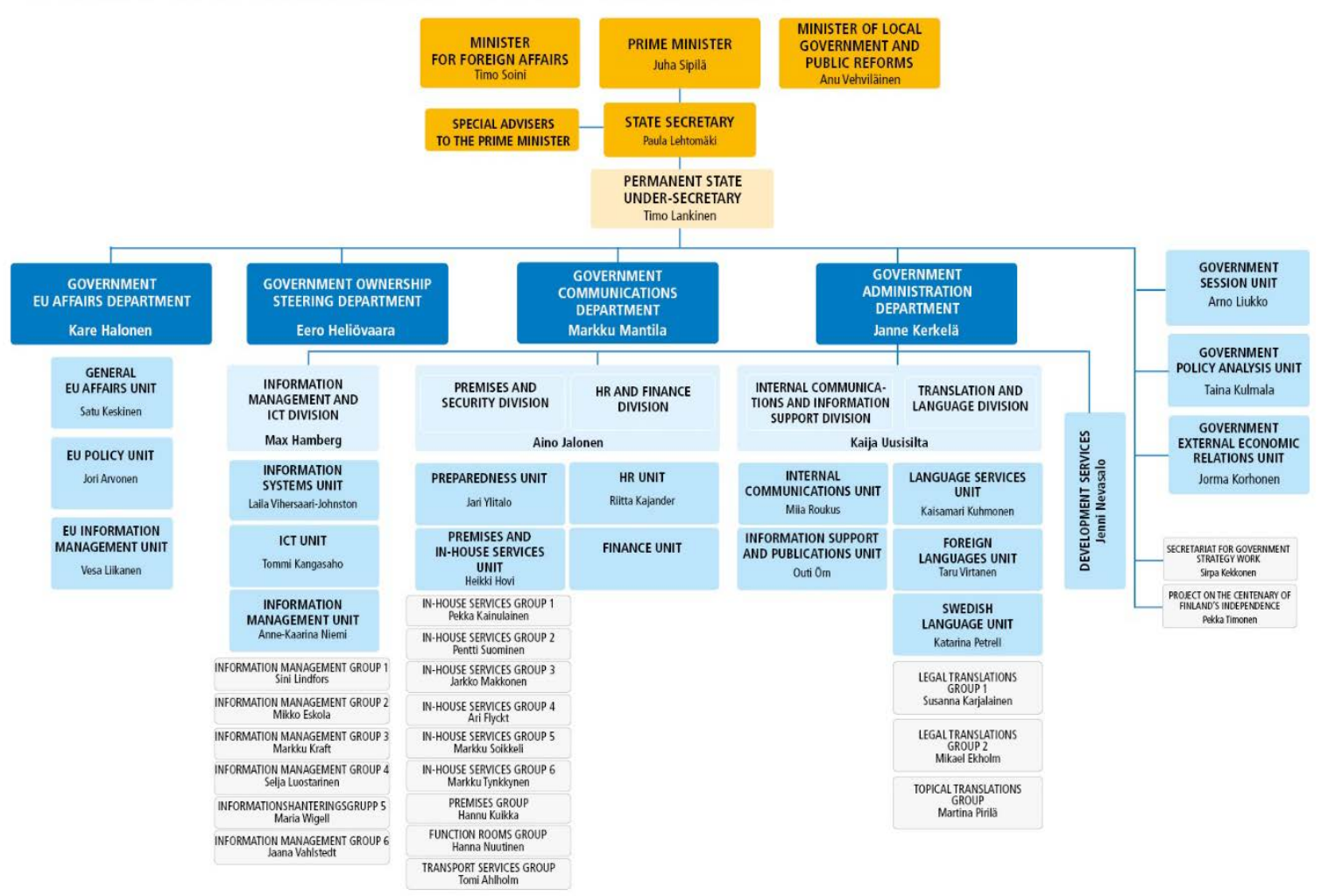

Source: $\underline{\text { Office of the Prime Minister of Finland. }}$

In the Finnish OPM, there are four large departments. The Government EU Affairs Department co-ordinates EU Affairs, similarly to the SEIO in Serbia. The Government Ownership Steering Department is responsible for state ownership policy and steers state-owned enterprises. In addition, there are separate departments for government communications and the handling of all administrative issues. Several core functions are fulfilled by separate smaller units. The Government Sessions Unit prepares the government sessions and ensures legality. The Government Policy Analysis Unit collects and analyses data, and monitors the long-term progress based on selected indicators. It also has the task of producing forward-looking reports. The Secretariat for Government Strategy Work is responsible for the government's strategy process, preparation of the government's action plan for the duration of its term, 
and a four-year rolling General Government Fiscal Plan ${ }^{12}$. It also monitors the implementation of these documents. The Secretariat is directly supervised by the Permanent State Under-Secretary ${ }^{13}$.

A second model can be seen in Montenegro, Serbia, and the former Yugoslav Republic of Macedonia, where the General Secretariat has more limited functions. Depending on the country, several key functions are fulfilled by other institutions, including ensuring legal conformity (all three), some aspects of planning government work (Serbia), or some aspects of co-ordinating policy development and decision making, specifically Regulatory Impact Assessment (RIA) (all three). This rather fragmented distribution of functions is also used by some of the EU and OECD countries. For example, Ireland has a system with a strong Legal Secretariat. In Estonia, strategic planning is partly handled by the MoF, and RIA by the MoJ. In Latvia, strategic planning is managed by the Cross-sectoral Policy Co-ordination Office.

Figure 2. Organisational chart of the Latvian State Chancellery and the Cross-sectoral Co-ordination Centre

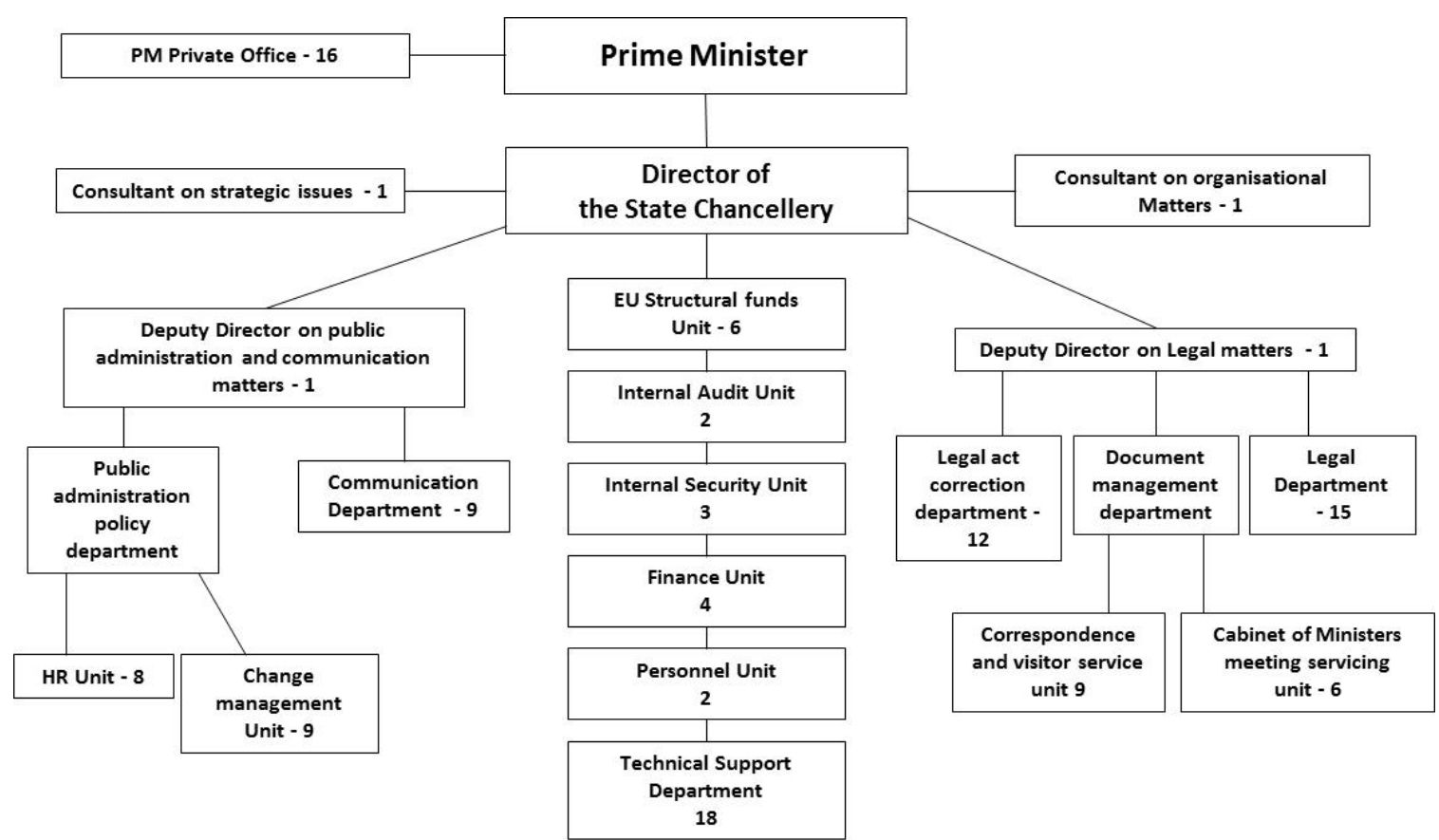

Cross-sectoral Co-ordination Centre (CCC)

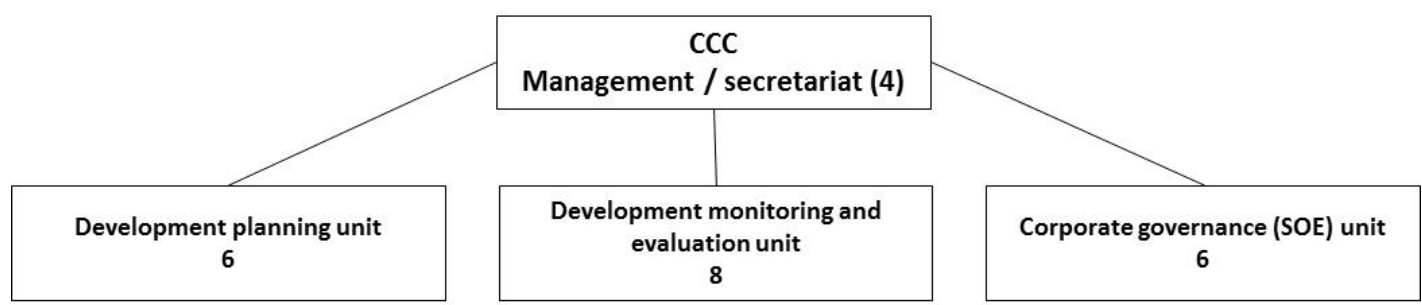

Source: Latvian State Chancellery.

The State level of Bosnia and Herzegovina departs also from the second model, where the Secretariat General of the Council of Ministers has even fewer CoG functions, since several other tasks, including economic planning, have been delegated to other institutions. However, the case of Bosnia and

12 For the overview of the General Government Fiscal Plan 2017-2020 (latest available): “Government agrees General Government Fiscal Plan for 2017-2020", Finnish Ministry of Finance.

13 For a more detailed description of functions: Management and organisation of the Office of the Prime Minister of Finland. 
Herzegovina has quite distinct specificities, as the state-level institutions lack the necessary constitutional tools to ensure whole-of-country co-ordination.

Institutional coherence or fragmentation does not by itself determine how well the system may function, for three reasons. First, even inside one institution, co-operation can be poor. For example, as the SIGMA country reports also spell out, such co-ordination challenges within the Office of the Prime Minister in Albania and Kosovo are leading to deficiencies in the effective functioning of the system ${ }^{14}$.

Second, distribution of functions into several institutions can be balanced with well-functioning inter-institutional (formal or informal) co-ordination mechanisms. Although this can be challenging, there are several efficient practices which the Western Balkan governments can use. One commonly-used practice is to hold regular, weekly meetings of the Secretaries General of all ministries, which also brings together key CoG figures. Albania and Kosovo have set up CoG co-ordination bodies for strategic planning ${ }^{15}$. These arrangements function in both Albania and Kosovo, as regular, joint discussion and decision-making platforms for institutions fulfilling the CoG functions (various units of the OPM, MoF, and $\mathrm{MEI}$ ). Montenegro has demonstrated good informal co-ordination, but its case is specific to its situation, having had the same long-time political leadership and small government structures.

Third, functioning depends on the capacity of the staff of the CoG, including having a sufficiently large staff for proper implementation, as well as the requisite legal and administrative tools at their disposal.

Staff allocation to different critical functions illustrates that the emphasis is on preparing the government sessions and ensuring legal conformity. Also, the functions to ensure financial affordability and co-ordination of EU affairs, which are handled by MoFs and EU integration offices/ministries, have adequate staff allocation. Other crucial functions are generally more modestly staffed, especially the co-ordination of the government's strategic priorities and work programme, co-ordination of policy content, and monitoring of government performance. Handling relations with the parliament and co-ordinating communication activities do not require high staff numbers. Nevertheless, for other functions (with few country exceptions) staff allocation, and also the distribution of tasks between the units, has an impact on the CoG performance.

For planning and monitoring the government's work and co-ordinating analysis of the policy content, the Western Balkan governments have approached the distribution of tasks between the units differently. In Serbia, the functions are largely separated from the General Secretariat and delegated to the PPS; in addition, the Delivery Unit has been established in the Cabinet of the Prime Minister. In Kosovo, the functions are split between the Government Co-ordination Secretariat, which also prepares the government sessions, and the Strategic Planning Office (SPO). Montenegro, Bosnia and Herzegovina and the former Yugoslav Republic of Macedonia all have a system where a separate structural unit prepares the government sessions and there is another unit dealing with planning, policy co-ordination and monitoring. Albania has a system where these critical CoG functions are distributed among several units, including units which are not present in most of the other countries, such as the Delivery Unit and the Office of the State Minister for Relations with the Parliament.

SIGMA (2015), Baseline Measurement Report: The Principles of Public Administration, Albania, OECD Publishing, Paris. The Decision of the Government of Kosovo No. 02/70 on the establishment of the Strategic Planning Committee, 15 January 2016; The Order of the Council of Ministers of Albania No. 18 on the establishment of the Strategic Planning Committee, 22 January 2014. 
Figure 3. Staff allocation to fulfilling critical CoG functions (as of 1 December 2015) ${ }^{16}$

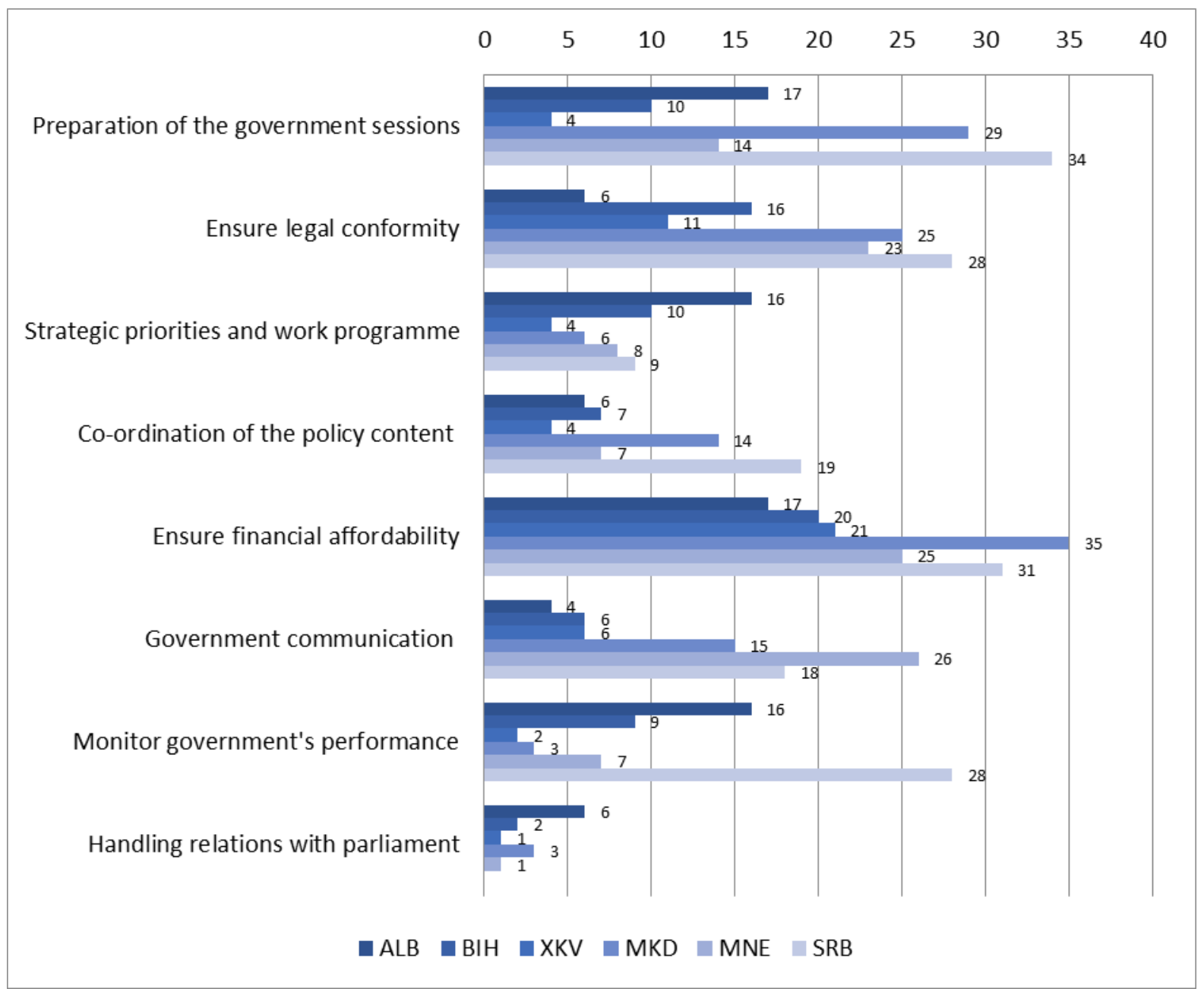

Source: Documents and data provided by the administrations in June-September 2016 (in exceptional cases data provided by the administration during the information collection for the SIGMA Baseline Measurement Reports are used).

Preparation of the government sessions ${ }^{17}$, the principal function in all the Western Balkan governments, is fulfilled in all of them. The centrality of the function in the Western Balkans is illustrated by the high numbers of staff. However, staff allocation for preparing the sessions varies, with almost 30 in the former Yugoslav Republic of Macedonia, and 34 in Serbia. This is often more than the total number of staff allocated to preparing the government's work programme, analysing policy content, and monitoring government performance. Even those with lower numbers of staff (ten in Bosnia and Herzegovina) exceed most of the EU centres of government. For example, in Estonia there are five officials and in Latvia six officials preparing the government sessions. In the EU countries, preparation of sessions is

Due to distribution of functions the staff allocation numbers are not cumulative and do not always mean a separate full-time position. In some cases, one official might deal with several tasks. For example, one official might plan for the work of the government, analyse policy content and monitor performance if all these functions are fulfilled by a single unit in the CoG.

In all six Western Balkan economies the governments sessions are prepared by the key CoG institution: in Albania and Kosovo by the OPM, and by the General Secretariat in Bosnia and Herzegovina, the former Yugoslav Republic of Macedonia, Montenegro, and Serbia. Within the key CoG institution the function is fulfilled in Albania by the Office of the Secretary General and Department of Legislation, Programme Monitoring and Anti-Corruption (DLPMA), Unit of Legislation and PM's Acts; in Bosnia and Herzegovina by Administrative Service; in Kosovo by the Government Co-ordination Secretariat; in the former Yugoslav Republic of Macedonia by the Department for Organisational and Normative Matters Related to the Sessions of the Government; in Montenegro by the Government Affairs Sector, Secretary General and Deputy Secretary General; and in Serbia by The Department of Preparation and Processing of Government Sessions and Government Working Body Sessions. 
often delegated to a separate, rather technical unit or department that concentrates only on that role. In several jurisdictions in the Western Balkans, a Government Secretariat type of department handles more functions often by organising these into smaller internal units.

Legal conformity ${ }^{18}$ is ensured by separate legal secretariats in four countries and by the OPM in Albania and Kosovo. Staff allocation numbers illustrate that it is a key function. There is a clear correlation between staff numbers and having a separate institution to ensure legal conformity. Where this is done in separate institutions, more resources (almost double) are needed to ensure the legality of government decisions than in countries without such an entity, but the bottom line is that this function is well embedded in all countries.

Setting strategic priorities and programming the work of the government ${ }^{19}$ is a crucial function to ensure that the government is able to deliver on its political commitments. However, fewer staff (a maximum of 16 officials) are generally allocated to this function than to checking legal conformity and session preparation. The institutional set-up for planning varies. Serbia partly allocates functions to a separate institution which is similar to the situation in Latvia. In Kosovo and the former Yugoslav Republic of Macedonia, these are allocated to separate departments. The former Yugoslav Republic of Macedonia model, with a so-called Central Planning and Monitoring Department, can be compared with the Finnish system of the Secretariat for Government Strategy Work in the CoG. However, in Kosovo the planning work is split between the Strategic Planning Office (setting priorities) and the Government Co-ordination Secretariat (developing the government's work plan), which creates additional co-ordination challenges within the CoG.

Co-ordinating the policy content of the proposals for government ${ }^{20}$ is the most challenging function, not only in the Western Balkans, but also in the public administration of many EU and OECD countries. Although most of the Western Balkan governments have established the function in the CoG, they all struggle with analysing and managing the policy content. This is due to several reasons: (a) an administrative culture where civil servants do not handle policy issues; (b) legal interpretations whereby the responsibility of line ministries for sector policies is considered absolute without the CoG institutions having the right to intervene more than on specific legal grounds; (c) limited capacity of staff and unclear allocation of the task between structural units.

EU countries have approached this challenging task either by creating a separate policy analysis unit like the Government Policy Analysis Unit in the Finnish State Chancellery, by merging policy planning and analysis into one department like the Strategy Office in the Estonian Government Office, or by streamlining all necessary functions in different policy sectors like in the Department of the Taoiseach in Ireland. In those Western Balkan governments where the policy co-ordination function is combined with planning and monitoring, policy analysis is not seen as a central task and the respective unit is not fully

18 In Albania, legal conformity is checked by the OPM, DLPMA, Unit of Legislation and Programme Monitoring; and in Kosovo by the OPM Legal Department.

19 There is a variety of structural units responsible for setting strategic priorities and programming the work of the Government. In Albania, these include the OPM Department for Development Programming, Financing and Foreign Aid, Unit for Policy Development and Strategic Planning and the Delivery Unit. In Bosnia and Herzegovina, they are the GS, Office of the CoM Chairman, section of strategic priorities and DEP. In Kosovo, they are the OPM, Strategic Planning Office and the Government Co-ordination Secretariat. In the former Yugoslav Republic of Macedonia they are the GS, and the Department for Strategy, Planning and Monitoring. In Montenegro, they are the GS, and the Sector for Planning, Co-ordination and Monitoring the Implementation of the Government Policy; in Montenegro, a strong role is also played by the Cabinets of the Prime Minister and the Deputy Prime Ministers. In Serbia these functions are carried out by the Public Policy Secretariat, the Sector for Planning and Co-ordination of Public Policies, and the General Secretariat.

The co-ordination of the policy content of the proposals for Government is also distributed between different units within the institutions or between institutions. In Albania, they are the OPM Department for Development Programming, Financing and Foreign Aid, Unit for Policy Development and Strategic Planning. In Bosnia and Herzegovina, the function is partly fulfilled by the GS and the Chairman Office of the CoM. In Kosovo it is performed by the OPM Strategic Planning Office and the Government Co-ordination Secretariat. In the former Yugoslav Republic of Macedonia it is done by the GS Department for Policy Analysis and Co-ordination. In Montenegro it is done by the GS and the MoF and in Serbia the function is partially fulfilled by the Public Policy Secretariat. 
involved in the daily policy co-ordination which would be necessary for proper policy analysis. In the centres of government where the function is tasked to the officials also doing the preparation work for the government sessions, staff do not have the necessary tools and capacities for policy analysis. In any case, a feasible and efficient institutional solution needs to fit into the overall organisational structure, but it is clear that this function needs to be in the key CoG institution, as close to the government as possible.

Financial affordability of policies ${ }^{21}$ is commonly ensured by a budget department in the MoF, and this is the case in the Western Balkans. In broad terms, all the analysed jurisdictions function similarly in this respect, having comparable numbers of staff allocated to budget planning and monitoring. The main challenge for most of the Western Balkans is the co-ordination between the key CoG institution and the MoF, leading to deficiencies in the actual alignment of the designed policies with budgetary resources. However, the Western Balkan economies do not differ substantially from many of the EU countries that struggle with similar challenges.

Communication departments/units ${ }^{22}$ are often assigned various tasks pertaining to relationships with citizens (for example, answering letters and complaints of citizens and ensuring access to information) that obscure the main task - communicating the government's message and explaining its objectives and policy measures to the public. This is one of the reasons for the significant differences in staff allocation for communication activities in the Western Balkans. This mixed responsibility for communication management and wider public relations can be found in several EU member states too.

Monitoring of government performance ${ }^{23}$ is crucial to ensure that the government delivers on its promises. This is a challenging function, as it requires properly designed and articulated aims and objectives to monitor their implementation. Structurally, there are two approaches to monitoring: either to create a separate department/unit to fulfil this function, or to give the task to the officials who are also responsible for setting the priorities and programming the work of the government. Most of the EU countries have chosen the latter option, as have Montenegro, Kosovo and the former Yugoslav Republic of Macedonia. However, Albania and Serbia use a third model, where the monitoring role is distributed amongst several units. This distribution does not fully correspond to the roles for priority setting and programming of the government's work. In addition, all of the Western Balkan governments have only basic monitoring capacities in place.

21 The financial affordability is ensured in all countries by the MoF, although the title of the department may vary. In Albania it is the Directorate of Budget Programming, Department of Budget Execution and Monitoring; in Bosnia and Herzegovina it is the Sector for Budget; in Kosovo it is the Budget Department; in the former Yugoslav Republic of Macedonia it is the Department of Budget and Funds; in Montenegro it is the Budget Directorate; and in Serbia it is the Sector for Budget.

22 The co-ordination of government communications is ensured by communications departments in either the OPM or the GS. In Albania, it is the OPM and the Department of Communication and Relations with the Citizens; in Bosnia and Herzegovina it is the GS, the Office of the CoM Chairman, Information services; in Kosovo it is the OPM and the Communication Department; in the former Yugoslav Republic of Macedonia it is the GS, the Public Relations Department, and the Unit for Media Relations, Co-ordination and Organisation of Information Activities; in Montenegro it is the GS and the Public Relations Bureau; in Serbia it is the GS and the Office for Cooperation with Media.

The monitoring of government performance is often distributed between different structural units. In Albania, these are the OPM, the Unit for Policy Development and Strategic Planning, the Unit of Legislation and Programme Monitoring, the Delivery Unit, the Office of the Minister of State for the Relations with the Parliament, and the Operational Situation Office. In Bosnia and Herzegovina, these are the GS and the Office of the Chairman of the CoM. In Kosovo this function is carried out by the OPM and the Government Co-ordination Secretariat. In the former Yugoslav Republic of Macedonia it is handled by the GS, the Department for Strategy, Planning and Monitoring, and the Unit for Strategic Planning and Monitoring. In Montenegro the Sector for Planning, Co-ordination and Monitoring the Implementation of the Government Policy is responsible. In Serbia, the Public Policy Secretariat, the Sector for the Quality Assurance of Public Policies, the Sector for Planning and Coordination of Public Policies and the Sector for Development, Promotion and Designing of Public Policies monitor Government performance. 
Handling relations with parliament ${ }^{24}$ varies among the EU Member States. Several countries use a model where a couple of officials in the Government Secretariat fulfil the function. For example, in Estonia there is one official in the Department of Government Sessions. The presence of ministers and the Prime Minister in the committee meetings and plenary sessions, if necessary, ensures parliamentary scrutiny ${ }^{25}$. Most of the Western Balkan governments use a similar model. In some countries, relations with the parliament are handled by a political figure. For example, in Portugal, relations with the Parliament are co-ordinated by the Secretary of State of Parliamentary Affairs - a member of the government, integrated in the Presidency of the Council of Ministers (key CoG institutions in Portugal), who holds a permanent seat at the meetings of the Council of Ministers without voting rights ${ }^{26}$. Albania uses a similar approach, having created a Minister without portfolio in charge of Parliamentary Relations.

To co-ordinate El, Albania and Kosovo, and recently Montenegro, have created a separate ministry. Until November 2016 in Montenegro, the El function was handled by the Ministry of Foreign Affairs. Serbia, Bosnia and Herzegovina, and the former Yugoslav Republic of Macedonia use a model where a secretariat/directorate (either independent or closely linked to the CoG) co-ordinates EU Affairs. Most of the EU countries use the latter model and do not have separate ministries dealing with EU affairs. However, in the Western Balkans, separate El ministries function as drivers of El-related reforms, or introduce new, well-functioning policy co-ordination and management practices.

Figure 4. Co-ordination of European integration, actual staff allocation (as of 1 December 2015)

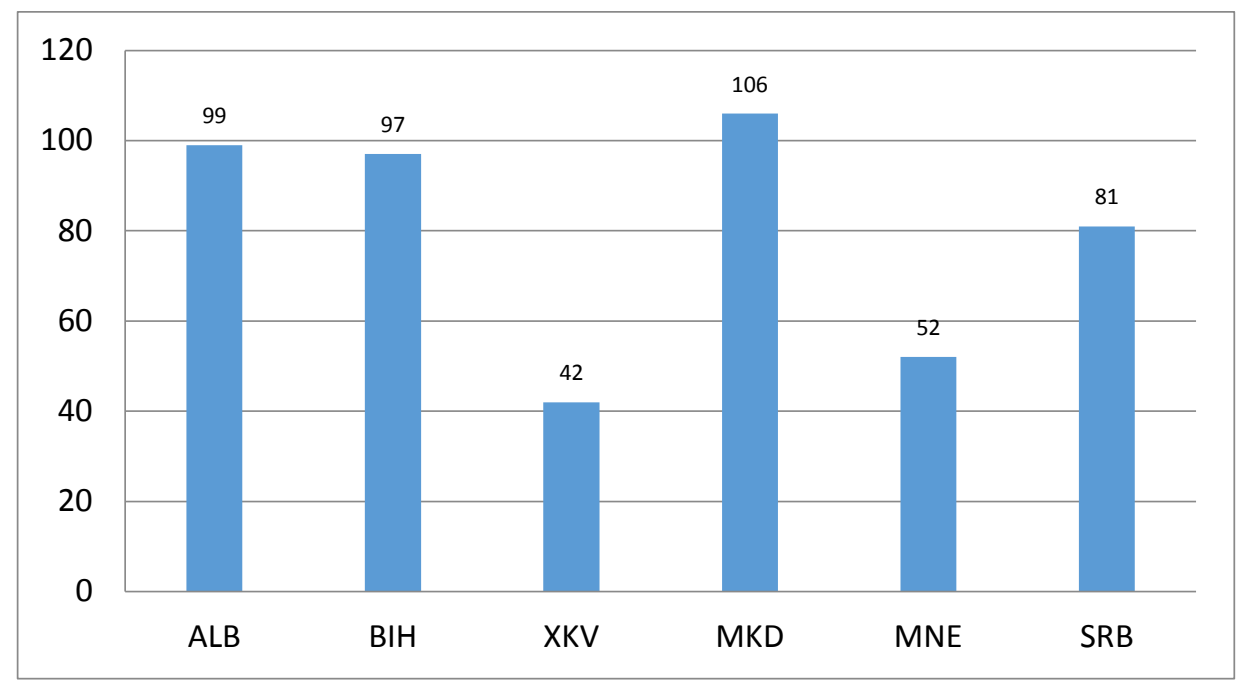

Source: Documents and data provided by the administrations in June-September 2016.

All countries implement the El function. However, the number of staff dealing with this varies from 42 to 106 officials (including both overall co-ordination of EU affairs and the dedicated teams co-ordinating planning and monitoring of EU-funded programmes). Two countries with relatively small administrations have fewer staff allocated to El, but in general, the El function is well-staffed compared with all other functions. However, there is no connection between the staff numbers and the progress of the country in the El process (for example, the countries already holding accession negotiations with the EU do not have more staff compared with the countries not having negotiations). Neither can it be concluded that having a separate ministry leads to more staff compared to other types of organisation.

Handling relations with Parliament is ensured by the Minister of State in Albania. In Bosnia and Herzegovina, the GS and the Administrative Service handle this role. In Kosovo it is the OPM and the Government Co-ordination Secretariat. In the former Yugoslav Republic of Macedonia the GS, the Unit for Co-operation with the Parliament; in Montenegro relations with Parliament are handled by the GS and the Government Affairs Sector. In Serbia they are handled by the GS.

25 Information provided by the Estonian Government Office.

26 Written analysis conducted by Joao Freire. 


\section{Preparing government decisions and ensuring conformity of the decisions}

\section{A. Ensuring the quality of proposals}

To ensure that government decisions are made in a transparent manner and that the professional judgement of the administration-including the scrutiny of legal conformity-is taken into account, clear rules must be in place. The role of the CoG is to develop these rules and guarantee that all those involved in the process adhere to the set procedures. These rules need to ensure that all necessary stakeholders have the opportunity to provide their opinion, but also that all relevant units of the CoG itself will have sufficient time to review the submitted proposals. To achieve a high quality of decision making, it is also necessary to set clear criteria for the documents submitted to the government sessions (such as the required documents and expected content of key complementary materials, e.g. the explanatory memorandum, impact assessment or information about the results of the consultation process). It is also necessary to empower the CoG body with the authority and capacity to review the content of the proposals against the set requirements and to take action if the requirements are not met. The CoG body also needs to have the authority to see that policy proposals are in accordance with the government's priorities and other policies.

Commonly, these rules are set in a law on government or the rules of procedure of the government, and the Western Balkans follow this practice. In most cases, the rules of procedure are detailed and set out in a robust framework for the government decision-making process. However, the rules do not always ensure sufficient time for providing opinions; do not set sufficient quality criteria for the proposals; provide the CoG body with a full mandate to ensure the expected quality.

Table 3. Procedural requirements in the Rules of Procedures in the Western Balkans

\begin{tabular}{|l|c|c|c|c|c|c|}
\hline & ALB & BIH & XKV & MKD & MNE & SRB \\
\hline $\begin{array}{l}\text { All necessary stakeholders } \\
\text { included (right to have opinion) }\end{array}$ & yes & yes & yes & yes & yes & yes \\
\hline $\begin{array}{l}\text { Clear and sufficient deadlines for } \\
\text { review of the CoG body (time } \\
\text { requirements for submission } \\
\text { before putting a draft to the } \\
\text { agenda of the government } \\
\text { session) }\end{array}$ & yes & yes & yes & yes & yes & no \\
\hline $\begin{array}{l}\text { Sufficient quality requirements } \\
\text { for the documents }\end{array}$ & partially & partially & yes & yes & yes & yes \\
\hline $\begin{array}{l}\text { Requirements for (regulatory) } \\
\text { impact assessment }\end{array}$ & no & no & yes & yes & yes & yes \\
\hline
\end{tabular}

Source: SIGMA (2015), Baseline Measurement Reports, OECD Publishing, Paris. Also documents and data provided by the administrations in June-September 2016.

In Albania and Bosnia and Herzegovina, the quality requirements are only partially set. According to SIGMA's 2015 Baseline Measurement Reports, the legal requirements are in place in Bosnia and Herzegovina, but detailed impact assessment and analysis rules and methodology have not been 
adopted and there are no requirements for fiscal impact assessment ${ }^{27}$. Albania faces similar challenges, where quality standards for impact assessment and corresponding analysis have not been set. Albania and Bosnia and Herzegovina are two countries where RIA requirements have not been formally set. Montenegro, the former Yugoslav Republic of Macedonia and Serbia are trying to use RIA comprehensively, having special units responsible for co-ordinating the development of RIAs and giving opinions on their quality. Kosovo has a system of Concept Papers that usually precedes the drafting of legal acts, including the need to have impact assessment. It is a commendable practice, as this system corresponds better to the capacities of the administration than requiring complex RIAs. If implemented well, it will provide sufficient information for making quality decisions ${ }^{28}$.

Impact assessment requirements in EU countries differ widely, from very detailed and comprehensive criteria in the United Kingdom and the Netherlands, to more modest frameworks in Latvia and Lithuania. The functioning of the RIA system depends on how well it corresponds to the capacities and resources of the administration. For example, in Slovakia all legislative and non-legislative documents submitted to the government must include an evaluation of impacts in five areas: budget, business environment, social impact, environment and the "informatisation" of the society. This information should be summarised in the "clause on selected impacts", which serves as a quick test for the preliminary impact estimation that needs to be accompanied by the opinions of relevant ministries. If impacts are expected in any of the five areas, further specific impact analysis should be conducted before submitting the materials for inter-ministerial and public consultation ${ }^{29}$. Estonia applies similar principles with initial, light impact mapping in six areas. The difference in the Estonian system is the requirement to develop a legislative intent that must include a preliminary impact assessment highlighting significant potential impacts. Legislative intents need to be consulted with the MoJ. Thus, the system is similar to Kosovo's concept paper approach ${ }^{30}$.

The main challenge for all the Western Balkan governments is to fully and consistently implement the set procedures. Requirements for involving the necessary stakeholders in the policy-development process are generally adhered to. However, even in this aspect there are challenges, such as checking the fulfilment of the set quality requirements and keeping the deadlines for providing opinions before the government session. In Serbia, no deadline is set for the submission of the materials, often leading to the submission only one day before deliberation by the government; this does not allow for proper quality scrutiny $^{31}$. The EU countries use different practical operational tools to ensure enough time for various CoG units to analyse the items and provide opinions. For example, in the Estonian CoG, all the items that are planned to be discussed on the regular government session on Thursday need to be submitted at least by the prior Friday. The decision on whether the item is to be included in the agenda is made on Wednesday and a pre-condition for inclusion in the agenda is that there are no issues raised by the CoG units $^{32}$.

Despite set rules, centres of government in some countries struggle to ensure that deadlines are kept, and to check whether the requirements are adhered to. Only the centres of government in the former Yugoslav Republic of Macedonia, Montenegro and Kosovo collect statistics on the timely submission of proposals for government sessions. In Montenegro and the former Yugoslav Republic of Macedonia,

SIGMA (2015), The Principles of Public Administration, Baseline Measurement Report: Bosnia and Herzegovina, OECD Publishing, Paris, pp. 32-34. For more in-depth analysis of Kosovo's concept paper system see SIGMA (2015), Policy Making Review Kosovo, SIGMA Paper No. 52, OECD Publishing, Paris, pp. 45-46. OECD (2015), Slovak Republic: Better Co-ordination for Better Policies, Services and Results, Public Governance Reviews, OECD Publishing, Paris, pp. 85-87.

30 For a more detailed description of the Estonian impact assessment system, see the presentation by Helena Braun, Advisor on Regulatory Impact in the Ministry of Justice: http://www.just.ee/sites/www.just.ee/files/jum ettekanne 18.09.2014 oma.pptx. SIGMA (2015), The Principles of Public Administration, Baseline Measurement Report: Serbia, OECD Publishing, Paris, p. 26.

32 Information provided by the Estonian Government Office. 
timely submission reached $95 \%$, while in Kosovo it reached $92.7 \%$ in the fourth quarter of $2015^{33}$. Large-scale non-compliance with the submission deadline hinders the CoG body's ability to ensure proper analysis and to provide opinions about the quality of proposals.

The volume of the items the CoG must review can also substantially affect the quality of decision making. Depending on what type of items need the approval of the government, the volume of the items differs remarkably in the Western Balkans.

Figure 5. Items submitted to the government $\left(4^{\text {th }}\right.$ quarter $)$

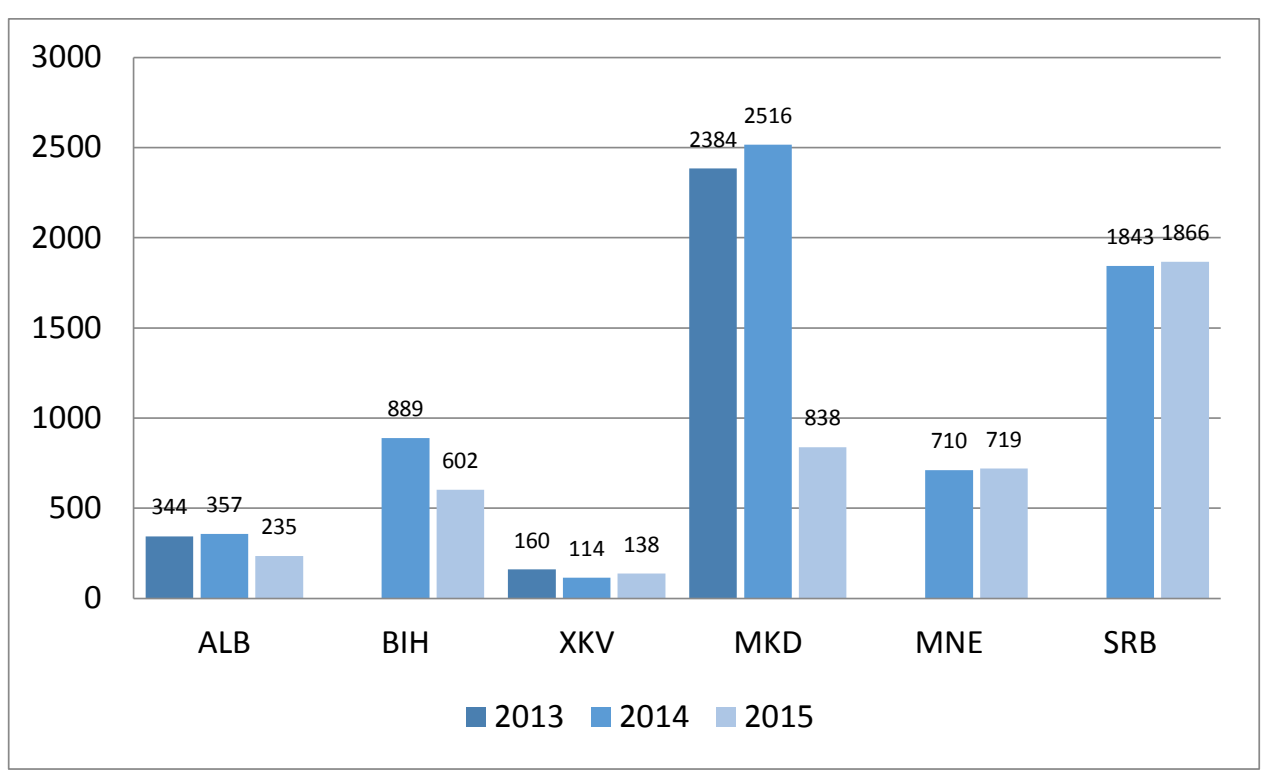

Source: SIGMA (2015), Baseline Measurement Reports, OECD Publishing, Paris. Also documents and data provided by the administrations in June-September 2016.

Albania, Kosovo, Montenegro, and Bosnia and Herzegovina have largely manageable numbers of items, even though the volume difference between the countries is substantial. In the former Yugoslav Republic of Macedonia ${ }^{34}$ and in Serbia, it is hardly possible for the CoG to ensure the proper review of all items, in particular from the policy analysis point of view, as the number of weekly items reaches 200 and the number of staff dealing with the review is relatively small ${ }^{35}$. The number of processed items strongly correlates with the role and authority of the responsible CoG body. In those countries where all detailed technical questions are discussed in the government sessions, the CoG acts as a technical secretariat and does not have a clear mandate to analyse the policy content or return the materials to the ministries because of poor quality. This is the case in both Serbia and the former Yugoslav Republic of Macedonia, where the CoG mandate to verify the details, and challenge the policy content, of the proposals is unclear. Furthermore, both in Serbia and in the former Yugoslav Republic of Macedonia, the governments are heavily overburdened by technical questions ${ }^{36}$.

As an example of an EU Member State initiative to reduce the burden of the government and to provide more time and resources for the CoG units to analyse the policy proposals, in 2008 the Estonian Government Office conducted a review to assess which items necessarily need the government's

Data provided by the respective administrations of the Western Balkan countries and Kosovo in June-September 2016.

The lower volume of items in the former Yugoslav Republic of Macedonia in 2015 compared to 2014 relates to the turbulent political situation that has influenced the work of the Government, and cannot be attributed to any actual change in the approach to Government decision making.

Even where the total number of staff responsible for the scrutiny of the proposal is relatively higher, on average at least ten proposals should be checked by every official in the respective CoG unit.

Even travelling reports of Deputy Secretary Generals make it to the Government's session and require approval by the Government. 
approval and/or discussion. After the review the number of items was substantially reduced. The review also addressed which items need practical analysis by the CoG and which are of a technical nature, still requiring formal government adoption, but can be automatically submitted to the government session without the CoG analysis. These two changes enabled the CoG units to concentrate more on the quality of the government's decisions ${ }^{37}$.

The mandate of the CoG body is a crucial factor in guaranteeing the quality of decision making. The CoG body needs to act as a final gatekeeper before the government sessions by returning the materials to the sponsoring ministry in case the substance is flawed, or does not meet the priorities of the government or the set quality (and procedural) requirements.

Table 4. Authority of the CoG body to return items to the ministries

\begin{tabular}{|l|c|c|c|c|c|c|}
\hline & ALB & BIH & XKV & MKD & MNE & SRB \\
\hline $\begin{array}{l}\text { Right to return items when } \\
\text { formal requirements are not } \\
\text { met }\end{array}$ & yes & yes & yes & yes & yes & yes \\
\hline $\begin{array}{l}\text { Right to return items when } \\
\text { content is flawed or does not } \\
\text { meet priorities }\end{array}$ & yes & no & yes & no & yes & no \\
\hline
\end{tabular}

Source: SIGMA (2015), Baseline Measurement Reports, OECD Publishing, Paris. Also documents and data provided by the administrations in June-September 2016.

In addition to Serbia and the former Yugoslav Republic of Macedonia, the Bosnia and Herzegovina CoG also lacks the mandate to return items based on a review of their policy content. This limitation fundamentally determines the extent to which the CoG can actually be involved in co-ordinating the policies of the government.

Regulations in all Western Balkans countries require that opinions from the Legal Secretariat (or OPM legal department), the MoF and the MEl be provided on all draft proposals. These institutions, in particular Legal Secretariats, are influential and act as practical gatekeepers. The power of the Legal Secretariats also stems from the fact that in the Western Balkans decision making is still legalistic. Where its mandate is more modest, the CoG only checks if the opinions from the relevant co-ordinating stakeholders are included, but does not enter into the substance of these opinions and does not act as a consensus broker if the opinions differ or certain issues remain unresolved. Even when the CoG does not have the right to send back items, some CoG bodies outside the OPMs/General Secretariats can still have a right to issue an opinion, for example in the framework of RIA quality checking. This is the case in Serbia, Montenegro and the former Yugoslav Republic of Macedonia, where the opinions are issued by the PPS (Serbia), the MoF (Montenegro) and the MISA (the former Yugoslav Republic of Macedonia). However, these opinions on the quality of RIAs are not binding and the institutions cannot stop the decision-making process if their opinion is disregarded. Such situations can be avoided if there is effective co-ordination between the bodies fulfilling the CoG functions. In these cases, the key CoG body in charge of the preparation of the government session should closely follow what is provided in the RIA opinion, and ensure that it is taken into account by the sponsoring ministry before the final materials are submitted to the government session.

EU countries have different practices concerning the mandate of the key CoG institution. For example, the Estonian Government Office has the authority to return the items to ministries when the content is flawed and does not meet the priorities. In the case of Portugal, this authority is less explicit and the 
mandate to return the items by the State Secretary of the Presidency of the CoM in charge of checking the proposals is limited to checking deadlines, the form of the proposals, lack of compliance with the Constitution or with higher-level laws, and any evident deficiencies ${ }^{38}$.

In practice, the right (whatever the mandate) to return drafts is not (and should not be) often used by the centres of government. The share of returned items varies from $1 \%$ to $10 \%$. Kosovo's $25 \%$ share in 2014 related to the change of government in that year.

Table 5. The number and share of returned items in 2014 and 2015 ( $4^{\text {th }}$ quarter)

\begin{tabular}{|l|c|c|c|c|}
\hline & \multicolumn{2}{|c|}{2014} & \multicolumn{2}{c|}{2015} \\
\hline & Number & Share & Number & Share \\
\hline ALB & 17 & $4.70 \%$ & 18 & $7.65 \%$ \\
\hline BIH & N/A & N/A & N/A & N/A \\
\hline XKV & 29 & $25 \%$ & 10 & $7.25 \%$ \\
\hline MKD & 23 & $0.90 \%$ & 14 & $1.70 \%$ \\
\hline MNE & 40 & $5.60 \%$ & 35 & $4.70 \%$ \\
\hline SRB & N/A & N/A & N/A & N/A \\
\hline
\end{tabular}

Source: SIGMA (2015), Baseline Measurement Reports, OECD Publishing, Paris. Also documents and data provided by the administrations in June-September 2016.

The proportion of items returned illustrates the strength of the mandate of the CoG body, and that this right empowers the $\mathrm{CoG}$ in guiding the ministries towards making changes in their proposals based on the problems pointed out by the CoG. However, it also reflects the administrative culture and working traditions of a given country, as many issues can be solved through informal discussions and working level co-operation, without using the last resort of sending back proposals at the final stage of policy development.

\section{B. Transparency of government decision-making}

To ensure that the public has the opportunity to be informed about the decisions of the government, and can seek information about the issues to be discussed by the government even before its decisions are made, it is crucial that the government provide as much information as possible. As a minimum necessity, the agenda and materials for the government sessions should be circulated to the participants in advance, and the agendas of sessions should be made public. In addition, decision records of the government meetings should be kept and notes from the meetings distributed after the sessions. The decisions should be made publicly available. 
Table 6. Publication of government session agendas and minutes

\begin{tabular}{|l|c|c|c|c|c|c|}
\hline & ALB & BIH & XKV & MKD & MNE & SRB \\
\hline Agendas & no & yes & yes & no & yes & no \\
\hline $\begin{array}{l}\text { Decision } \\
\text { records/minutes }\end{array}$ & yes & yes & yes & no & yes & no \\
\hline
\end{tabular}

Source: SIGMA (2015), Baseline Measurement Reports, OECD Publishing, Paris. Also documents and data provided by the administrations in June-September 2016.

Most of the Western Balkan governments adhere to these transparency principles and publish both agendas and minutes (or government decisions after each session). Several countries organise media briefings for journalists. Kosovo and Bosnia and Herzegovina allow government sessions to be followed via the internet. The Albanian OPM does not publish session agendas. The former Yugoslav Republic of Macedonia and Serbia have opted for a more reserved approach and do not publish either agendas or minutes but only government decisions on a selective basis.

This practice is not fully alien to EU countries. For example, the Hungarian Government does not publish agendas or minutes of its meetings, and only provides information through press briefings. Moreover, in Hungary, records of government sessions are not kept. In Portugal the agendas, debates, decisions, and syntheses of government sessions are subject to confidentiality. The synthesis of the adopted decisions and final conclusions, drafted by the Secretary of State of the Presidency of the Council of Ministers, replaces the minutes of the session, and is accessible only to the members of the government. The confidentiality clause also covers the draft acts submitted to the Council of Minister's sessions. A final press release is issued at the end of each meeting of the government, listing the adopted drafts, or any other relevant conclusions ${ }^{39}$.

At the other extreme, journalists, interest groups and the wider public in Estonia have the agenda of the meeting a day in advance of the session, as well as access to all the materials set for deliberation through an electronic information system. The decision making can be followed on-line ${ }^{40}$. 


\section{Planning medium-term policies and sector strategies}

Medium-term planning has two main dimensions. The most important aspect is planning the work of the government and setting the priorities that are central tasks of the key CoG body or bodies. To successfully undertake these tasks, a robust legal framework must be in place that establishes the status of the key planning documents and develops a coherent planning system, as well as the approach to, and procedures for, translating the government's political programme into administrative actions. The framework needs to be complemented by clear guidelines provided by the CoG body to the participants of the process. The second dimension is the planning of sector policies. The importance of this cannot be underestimated. In this process, the role of the CoG is to ensure the coherence of the sector policies and the overall quality of planning.

\section{Practice in EU countries}

EU Member State governments use very different planning systems, which nevertheless have several common features: mechanisms to ensure the coherence of the documents (including between central medium-term plans and sector strategies); mechanisms for ensuring financial affordability of the policies; and established links between political priorities and administrative documents.

As an example, Estonia has only one central planning document, the Government Action Plan, which is directly linked to the political priorities of the government and expressed in the Government Programme for the term of the government. It aligns administrative priorities with political ones. The Government Action Plan, which is prepared and monitored by the Strategy Unit, is a medium-term document covering the whole mandate of the government, but it is updated annually on the basis of the assessment of achievements in previous year against the targets set for the whole four-year term (hence no rolling target setting is in place). The Plan also includes tasks derived from EU membership, and eases the planning burden by substituting separate plans with one single document. Three longer-term strategies serve as an umbrella for both the Government Action Plan and for the sector strategies. 
Figure 6. Example of Estonian strategic planning documents

\section{Figure 5.4. Strategic planning in Estonia showing area of responsibility}

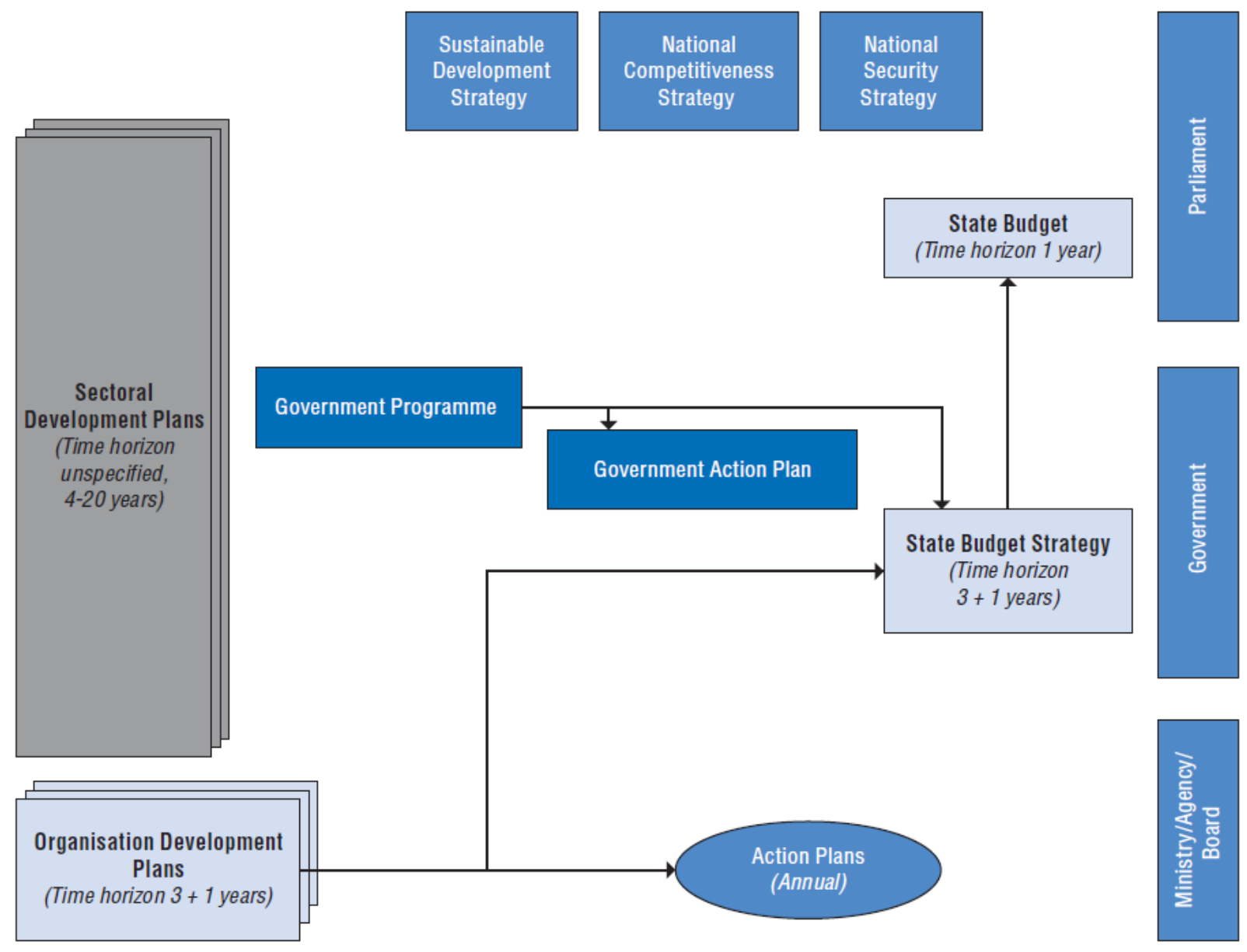

Source: OECD (2011), Estonia. Towards a Single Government Approach, OECD Public Governance Reviews, Public Governance Reviews, OECD Publishing, Paris.

The Lithuanian planning system has some characteristics that are similar to the Estonian model: by having a long-term umbrella strategy (State Progress Strategy Lithuania 2030), and by linking the sector policies with the Government Programme, supplemented by inter-ministerial action plans. However, Lithuania has developed a separate document for setting annual government priorities. The aim of the National Progress Programme is to align the programming of EU funds with domestic policy priorities and documents. 
Figure 7. Example of Lithuanian strategic planning documents

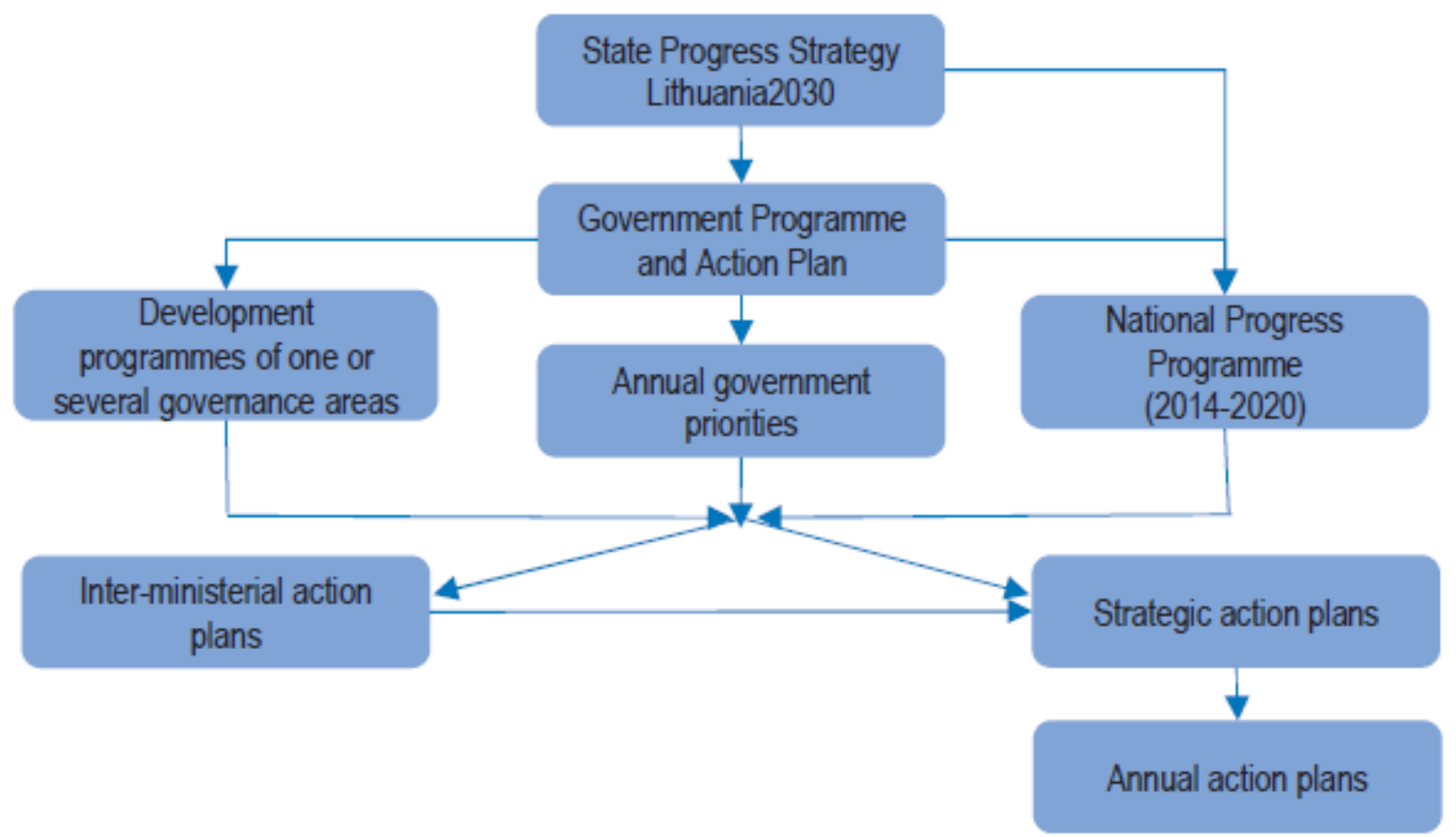

Source: OECD (2015), Lithuania: Fostering Open and Inclusive Policy Making, Public Governance Reviews, OECD Publishing, Paris.

In Slovakia, however, the links between the planning documents are not so straightforward. Slovakia has government work programmes that are compiled to implement the government's Manifesto, which sets out the political aims of the government. The Manifesto reflects the election programme of the political party gaining a majority in a general election, or the results of the coalition negotiations in case one party cannot form a government. Government programmes are prepared by the ministries and the Government Office simply aggregates departmental work. In addition, the Slovakian MoF develops the National Reform Programme that has limited links with the Manifesto and government programmes ${ }^{41}$.

A. Medium-term planning of the government's work

Most of the Western Balkans countries use several central planning documents that make ensuring coherence more challenging. 
Table 7. Central planning documents in the Western Balkans

\begin{tabular}{|l|c|l|}
\hline Country & $\begin{array}{c}\text { No of } \\
\text { documents }\end{array}$ & \multicolumn{1}{|c|}{ List of central planning documents } \\
\hline ALB ${ }^{43}$ & 6 & $\begin{array}{l}\text { The 600-Day Plan, the six cross-government priorities, the 56 } \\
\text { ministerial priorities, the National Plan for EU Integration, the } \\
\text { Annual Plan for Legal Acts, the National Strategy for } \\
\text { Development and Integration }\end{array}$ \\
\hline BIH (state level) & 2 & $\begin{array}{l}\text { The Medium Term Work Programme of the CoM, the } \\
\text { Government Annual Work Plan }\end{array}$ \\
\hline XKV & 4 & $\begin{array}{l}\text { The Medium-term Declaration of Priorities of the Government, } \\
\text { the National Plan for the Implementation of the SAA, the } \\
\text { National Development Strategy, the Government Annual Work } \\
\text { Plan }\end{array}$ \\
\hline MKD & 3 & $\begin{array}{l}\text { The Government Strategic Priorities, the Government Annual } \\
\text { Work Plan, the National Plan for the Adoption of the acquis }\end{array}$ \\
\hline MNE & 3 & $\begin{array}{l}\text { The Government Annual Work Plan, the Programme of Accession } \\
\text { of Montenegro, the Montenegro Development Directions }\end{array}$ \\
\hline SRB & 3 & $\begin{array}{l}\text { The Action Plan for the Implementation of the Government } \\
\text { Programme, the Government Annual Work Plan, the National } \\
\text { Plan for the Adoption of the acquis }\end{array}$ \\
\hline
\end{tabular}

Source: SIGMA (2015), Baseline Measurement Reports, OECD Publishing, Paris. Also documents and data provided by the administrations in June-September 2016.

When analysing the status and set-up of central planning documents, three aspects have particular relevance. The first aspect is the number of documents and the lack of overall coherence, which is partly due to the fact that none of the Western Balkan economies has a clear typology or hierarchy for their central planning documents. Obviously, it is more difficult to ensure coherence of content and the alignment of objectives when there are numerous documents. Albania and Kosovo have the highest number of central planning documents, making it more difficult for them to ensure coherent and consistent planning. Particularly in recent years, planning has been an experimental field for several countries, leading to new, ad hoc plans which are not fully aligned with other central planning documents. Examples of this are the 56 ministerial priorities in Albania, the four-year plan in Kosovo, and the Action Plan for the Implementation of the Government Programmes in Serbia. All such plans were developed in parallel with the already functioning (yet not fully efficient) planning system. Nevertheless, ensuring that the government priorities are duly represented in other planning documents is not impossible even in the case of fragmented planning systems. This is demonstrated by Albania, where the implementation of the six cross-government priorities is ensured by consistently including the key policy milestones and deliverables into the Annual Plan for Legal Acts, as well. The coherence between the El-related plan and the national/government work programmes in the Western Balkan economies is another area where shortcomings are found. The SIGMA 2015 Baseline Measurement reports indicate

\footnotetext{
42 In the framework of the European integration process, all accession countries have to develop their Economic Reform Programme. These plans are not included in the analysis here in order to focus only on the central planning documents arising from the national planning systems.

43

In Albania, several central planning documents (the 600-Day Plan or the 56 ministerial priorities) have not been formally adopted, but are the actual basis for the Government's work.
} 
that all jurisdictions have some issues with coherence in that respect. The scale of discrepancies differs. As an illustration, comparison of the Albanian National Plan for EU Integration with the Analytical Plan for Legal Acts revealed that the first included 29 strategies, while the latter had only nine strategies for adoption in 2016.

The second aspect of this analysis examines the robustness of translating the political priorities of the government into administrative priorities and actions. Governments use different approaches to ensure that their political objectives are implemented. Kosovo, Serbia and the former Yugoslav Republic of Macedonia have developed a separate document that sets the priorities for the administration. Bosnia and Herzegovina and Montenegro do not use priority statements, while Albania has developed a system with several priority-setting documents of varying duration and levels of generalisation. When having a separate document on government priorities, it is crucial that these priorities are reflected in other planning documents. The analysis shows that achieving full coherence in this respect remains a challenge for all the jurisdictions using such a system. Rooting the development of both the priorities and the work plan in the same structural unit makes it easier to ensure alignment. However, the two tasks are often distributed between different units (priorities to strategic planning units, such as the Strategic Planning Office in Kosovo, and work planning to government secretariats). In such cases, very close co-operation between the units is necessary in order to make this shared planning work ${ }^{44}$. When the plans are aligned with the priorities, the prioritisation function requires at least some level of top-down planning, and very active co-ordination by the CoG body. In contrast, the SIGMA 2015 Baseline Measurement reports highlight strong bottom-up tendencies in planning, with varying extents of practical co-ordination by the CoG in the Western Balkan governments. Even those centres of government that have an active co-ordination role struggle with guiding the ministries to concentrate on the priorities when delivering their proposals for actions for the upcoming planning period.

The third characteristic to be analysed is the strength of the medium-term planning perspective. Montenegro lacks a medium-term operational planning framework, since the nature of the Montenegro Development Directions is more general ${ }^{45}$. Other jurisdictions have some type of medium-term operational plan. For example, Bosnia and Herzegovina adopted such a plan in early 2016, which proved to be an important improvement ${ }^{46}$. However, alignment of medium-term and annual plans is generally problematic and suffers from serious shortcomings. Alignment is particularly an issue in Albania and Kosovo, which have numerous medium-term plans and some of them do not link directly with the annual plan that is still the main tool for operational planning of the work of the government. The same challenges attributed to the set-up of the functions, as we saw above, also apply here. In several jurisdictions (Albania, Kosovo, Serbia) the CoG units developing medium-term plans and the annual plan are different. In Serbia, there is a separate institution, the PPS responsible for medium-term planning. That leads to unnecessary tensions in the system and creates co-ordination challenges when attempting to ensure coherence of medium-term and annual planning.

There is no ceiling or limit for the number of central planning documents. However, the experience of EU countries illustrates that less is better. The requirement to develop a long-term plan for the use of EU funds in the Member States also supports the streamlining of planning. The variety of approaches to planning reflects the different administrative traditions.

\section{Medium-term budget planning documents}

Most of the Western Balkan governments also adopt annual, rolling, medium-term expenditure frameworks (MTEFs) that have a varying degree of quality, but can be considered as central planning documents in terms of government priority objectives and sectoral or organisational policy objectives.

44

In Kosovo the Technical Review Teams of the CoG that provide consolidated comments to the line ministry proposals serve this purpose.
45

46

Montenegro Development Directions 2015-2018 were adopted by the Government on 2 July 2015

Medium Term Work Programme of CoM Bosnia and Herzegovina for 2016-2018 adopted at the 41st session of CoM Bosnia and Herzegovina 2016. 
Table 8. Inclusion of policy objectives in the medium-term expenditure frameworks of the Western Balkans

\begin{tabular}{|l|c|c|c|}
\hline & Existence of a MTEF & $\begin{array}{c}\text { Priority policy } \\
\text { objectives included }\end{array}$ & $\begin{array}{c}\text { Sectoral and organisational } \\
\text { policy objectives included }\end{array}$ \\
\hline ALB & yes & yes & yes \\
\hline BIH & yes & no & yes \\
\hline XKV & yes & yes & no \\
\hline MKD & yes & yes & no \\
\hline MNE & yes & yes & no \\
\hline SRB & yes & yes & nos \\
\hline
\end{tabular}

Source: Latest available medium-term expenditure framework of the Western Balkan economies ${ }^{47}$.

The MTEF is in place in all the Western Balkan economies and most of them also indicate the government's priority objectives. Albania and Kosovo also cover sectoral or organisational objectives; moreover, Albania, as well as Serbia have started to implement programme-based financial planning and have incorporated programmes (or, in the case of Serbia, at least priority reform areas) into the MTEF.

The EU Member States are obliged to present their medium-term budgetary plans to the Commission and Council Directive 2011/85/EU sets the requirement for budgetary frameworks. However, in terms of the details and formulation of the medium-term budgets, the Member States enjoy considerable latitude.

B. Implementation of the central planning documents

The functioning of a planning system is best assessed by its outcomes. The number of central planning documents has no relevance if they are not implemented. It is a key role of the CoG to ensure that the government is able to deliver on its plans. This requires high-quality planning and also efficient co-ordination. The efficiency of the planning system can be measured by the proportion of items carried forward. This shows how many planned items are not delivered on time and are carried over to the following year.

Medium-term Budget Programme 2016-2018 of Albania

Global Framework of Fiscal Balance and Policies in Bosnia and Herzegovina 2017-2019

Medium-Term Expenditure Framework 2017-2019 of Kosovo

Fiscal Strategy Paper for 2016 with projections for 2017 and 2018

Directions for Fiscal and Economic Policy of Montenegro 2015-2018

Fiscal Strategy of the former Yugoslav Republic of Macedonia 2015-2017. 
Table 9. Proportion of items carried forward in the Western Balkans ${ }^{48}$

\begin{tabular}{|l|c|c|c|c|c|}
\hline \multirow{2}{*}{} & \multirow{2}{*}{$\mathbf{2 0 1 4}$ laws } & \multicolumn{3}{|c|}{$\mathbf{2 0 1 5}$} & No. of items in \\
\cline { 3 - 6 } & & laws & by-laws & All & $\mathbf{2 0 1 5}$ \\
\hline ALB & Not available & $19.0 \%$ & $5.0 \%$ & $8.5 \%$ & 551 \\
\hline BIH & $14.0 \%$ & $34.0 \%$ & $21.5 \%$ & $25.0 \%$ & 217 \\
\hline XKV & $48.5 \%$ & $46.0 \%$ & Not available & $26.0 \%$ & 679 \\
\hline MKD & $16.0 \%$ & $16.0 \%$ & $10.9 \%$ & $4.2 \%$ & 550 \\
\hline MNE & $26.0 \%$ & $19.5 \%$ & $17.4 \%$ & $8.6 \%$ & 233 \\
\hline SRB & $49.0 \%$ & $33.9 \%$ & $20.8 \%$ & $25.5 \%$ & 853 \\
\hline
\end{tabular}

Source: SIGMA (2015), Baseline Measurement Reports, OECD Publishing, Paris. Also documents and data provided by the administrations in June-September 2016.

The general implementation backlog varies from $8.5 \%$ in Albania (considered as low) to $26 \%$ in Kosovo and $25 \%$ in Serbia and Bosnia and Herzegovina. When looking specifically at the backlog of the development of laws, the picture is less positive. This is illustrated by backlogs ranging from $16 \%$ in the former Yugoslav Republic of Macedonia to as high as $46 \%$ in Kosovo. Both Serbia and Bosnia and Herzegovina have backlogs over 30\% (33.9\% and 34\%). The former Yugoslav Republic of Macedonia has managed to keep its backlog of laws at the same level it had in 2014, which is the lowest level of the Western Balkans. Kosovo's backlog has remained broadly the same, but is the highest amongst the Western Balkan economies. Montenegro and Serbia have managed to reduce their backlogs. In contrast, the backlog has substantially increased in Bosnia and Herzegovina.

There are several reasons behind the high backlog figures. The SIGMA 2015 Baseline Measurement reports point out that in the Western Balkans the overall challenge is over-optimistic planning, which is partly caused by the weak co-ordination capacity and lack of authority of the CoG body in charge of planning. When the CoG only sets the procedures and collects the inputs from the ministries but does not handle priority-setting issues, there is a high risk of overloading central planning documents with the items. The analysis indicates a correlation between the backlog and the number of draft laws planned annually. In the former Yugoslav Republic of Macedonia, where the backlog is the smallest, 37 draft laws were planned for adoption. At the same time, Serbia planned to adopt 310 laws and 543 by-laws. In Kosovo, where the annual plan foresaw the adoption of 136 laws, the total number of items in the Government Annual Work Plan was as high as $679^{49}$.

If the administration lacks the capacity to implement all the items included in overly-optimistic plans in a timely manner, it can lose the focus of delivering its priorities. This is confirmed by statistics that highlight higher backlogs for more complex tasks, such as preparing draft laws, compared with other items. The CoG body has a central role to play in reducing implementation backlog.

In order to ensure comparability, one key operational central planning document is selected in each country, which is renewed each year: the Government Annual Work Plan (in Albania, the Annual Plan of Legal Acts). Items in the 2015 and 2016 plans are compared. As countries insert many different types of items into the plan, implementation backlog is calculated separately for the draft laws, by-laws and all items. The 2014 backlog is calculated only for laws using the Government Annual Work Plan for 2014 and 2015 respectively. 
There are two tools to reduce the backlog. The first is streamlining the number of items in the central plan(s) to fit the actual capacity of the administration, or to concentrate only on priorities. However, this is not an easy process and requires very active leadership by the CoG. For example, both the Estonian and Finnish governments aim to focus more on priorities and reduce the number of items in the Government Action Plan, though the practical results have been limited.

Figure 8. Measures in the government central planning document of Finland and Estonia over time

\begin{tabular}{cccccc|cccc}
\hline & \multicolumn{4}{c|}{ Finland } & \multicolumn{4}{c}{ Estonia } \\
\cline { 2 - 9 } & $2003-07$ & $2007-10$ & $2010-11$ & $2011-14$ & $2014-$ present & $2006-07$ & $2007-11$ & $2011-14$ & $2014-15$ \\
\hline Number of measures & 260 & 587 & $\begin{array}{c}587+ \\
27 \text { new }\end{array}$ & 964 & $\begin{array}{c}964+ \\
67 \text { new }\end{array}$ & 92 & 362 & 648 & 289 \\
\hline
\end{tabular}

Source: OECD (2015), Estonia and Finland: Fostering Strategic Capacity across Governments and Digital Services Across Borders, Public Governance Reviews, OECD Publishing, Paris.

In order to keep the policy development work of the government and the administration focused and manageable, both governments grouped the actions under a limited number of priorities and objectives. Estonia has grouped key measures under five priority objectives. Finland has chosen 140 key projects, that are grouped under three priority objectives which are linked with the medium-term budgetary framework and spending limits. In Finland, like in Estonia, there is one unit in the CoG responsible for the preparation and monitoring of the central planning document.

Figure 9. Government Programme and its implementation in Finland

\begin{tabular}{|c|c|c|c|}
\hline Strategy & Time horizon & Ministry/unit responsible & Goals and objectives \\
\hline $\begin{array}{l}\text { Government } \\
\text { Programme (GP) }\end{array}$ & 4 years & Coalition government & $\begin{array}{l}\text { While the GP was not structured under any limited } \\
\text { whole-of-government objectives, a selection of the most } \\
\text { important of its } 900 \text {-odd measures were grouped under } \\
\text { the } 3 \text { main objectives: } \\
\text { 1.1. Reduction of poverty, inequality and social exclusion } \\
\text { 1.2. Consolidation of public finance } \\
\text { 1.3. Enhancing sustainable economic growth, } \\
\text { employment and competitiveness }\end{array}$ \\
\hline \multirow[t]{2}{*}{$\begin{array}{l}\text { Strategic } \\
\text { Implementation Plan } \\
\text { of the Government } \\
\text { Programme (HOT) }\end{array}$} & 4 years & $\begin{array}{l}\text { Prime Minister's Office, } \\
\text { Policy Analysis Unit } \\
\text { (PAY) }\end{array}$ & $\begin{array}{l}\text { The HOT focuses on the Government Programme's } \\
\text { three main objectives, defining key measures and } \\
\text { projects to achieve these objectives, preparation } \\
\text { responsibilities, and schedules and aims at tuming them } \\
\text { into strategic, inter-sectoral and comprehensive policies. }\end{array}$ \\
\hline & & & $\begin{array}{l}\text { The HOT contains } 140 \text { key projects which are monitored. } \\
\text { The HOT was adopted at the same time as the spending } \\
\text { limits for the electoral term. }\end{array}$ \\
\hline $\begin{array}{l}\text { Mid-term spending } \\
\text { limits }\end{array}$ & Annual & $\begin{array}{l}\text { Ministry of Finance, } \\
\text { Budget Department }\end{array}$ & $\begin{array}{l}\text { Mid-term spending limits are decided upon at the } \\
\text { beginning of the government term for four years, } \\
\text { with a rolling annual review for the next four years. }\end{array}$ \\
\hline
\end{tabular}

Source: OECD (2015) Estonia and Finland. Fostering Strategic Capacity across Governments and Digital Services across Borders, Public Governance Reviews, OECD Publishing, Paris.

The second key tool to address shortcomings in implementation is to improve the co-ordination of the implementation and monitoring carried out by the CoG. Monitoring issues are covered in the following chapter of this paper in more detail, but generally, in order to be successful in co-ordinating implementation, the CoG needs to go beyond monitoring and should put strong emphasis on ensuring the efficient functioning of co-ordination structures supporting implementation. These structures can be built into the co-ordination mechanisms the CoG uses to improve co-operation, such as strategic planning committees (as in Albania and Kosovo), or regular meetings of the State Secretaries (as in the 
former Yugoslav Republic of Macedonia). The structures can be set up in a manner that complements existing co-ordination mechanisms. As an example of an EU Member State, Estonia uses co-ordination groups of Deputy Secretary Generals, which are based on the objectives set in the Government Action Plan.

\section{Development and implementation of sector policies}

In addition to central planning, the government needs to have sectoral policies that are medium term or long term in nature. As each ministry may want to have a different approach to policy planning and developing sectoral strategies, programmes or action plans, it is the role of the CoG to establish, formalise and co-ordinate the system for planning sector strategies. The CoG should also guide the development process of strategies to ensure coherence between sectoral plans to maintain quality control of their content. In order to be implementable and realistic, it is crucial that there are sufficient financial resources to ensure the execution of planned actions. Therefore, sectoral strategies should include financial assessments (budgetary costs and planned EU/donor assistance) that are consistent with the medium-term budgetary framework.

Table 10. Overview of sector policy planning systems in the Western Balkans and Kosovo

\begin{tabular}{|c|c|c|c|c|c|c|c|}
\hline Country & $\begin{array}{l}\text { Regulation } \\
\text { exists }\end{array}$ & $\begin{array}{l}\text { Level of } \\
\text { regulation }\end{array}$ & $\begin{array}{l}\text { Hierarchy of } \\
\text { plans }\end{array}$ & $\begin{array}{l}\text { Typology } \\
\text { of plans }\end{array}$ & $\begin{array}{l}\text { Detailed } \\
\text { requirements }\end{array}$ & $\begin{array}{l}\text { Costing } \\
\text { requirements }\end{array}$ & $\begin{array}{l}\text { Monitoring } \\
\text { requirements }\end{array}$ \\
\hline$A L B^{50}$ & yes & by-law & no & partial & yes & $\begin{array}{c}\text { partial (link } \\
\text { to MTEF) }\end{array}$ & partial \\
\hline $\mathrm{BIH}^{51}$ & yes & by-law & $\begin{array}{c}\text { yes } \\
\text { (partial) }\end{array}$ & yes & yes & $\begin{array}{c}\text { partial (link } \\
\text { to MTEF) }\end{array}$ & yes \\
\hline$X K V^{52}$ & yes & by-law & no & no & partial & $\begin{array}{c}\text { partial (link } \\
\text { to MTEF) }\end{array}$ & no \\
\hline$M K D^{53}$ & yes & $\begin{array}{l}\text { by-law + } \\
\text { manual }\end{array}$ & yes & yes & yes & $\begin{array}{c}\text { partial (link } \\
\text { to } \\
\text { budgeting) }\end{array}$ & partial \\
\hline MNE & no & $\mathrm{N} / \mathrm{A}$ & $\mathrm{N} / \mathrm{A}$ & $\mathrm{N} / \mathrm{A}$ & $\mathrm{N} / \mathrm{A}$ & $\mathrm{N} / \mathrm{A}$ & $\mathrm{N} / \mathrm{A}$ \\
\hline$S R B^{54}$ & no & N/A & $\mathrm{N} / \mathrm{A}$ & N/A & N/A & $\mathrm{N} / \mathrm{A}$ & N/A \\
\hline
\end{tabular}

Source: Analysis of legal frameworks of the Western Balkan economies, SIGMA (2015), Baseline Measurement Reports, OECD Publishing, Paris.

Order of the Prime Minister No. 93 on drafting the national sector and cross-sector strategies for the period 2013-2020 and sector strategic documents 2013-2020 in the framework of the National Strategy for Development and Integration 2013-2020, 7 August 2012.

51 The Council of Ministers decision on the procedures of medium-term planning, monitoring and reporting in the institutions of Bosnia and Herzegovina, 23 July 2014. The Bosnia and Herzegovina system for medium-term planning is institution-driven, not sector policy specific.

52 The Administrative Instruction No. 02/2012 on the procedures, criteria and methodology for the preparation and approval of strategy documents and plans for their implementation; Manual for the preparation of sectoral strategies, June 2013.

53 The Methodology for strategic planning and preparation of the annual work programme of the Government, adopted on 3 October 2008. The system is fully institutional and does not devote attention to sectoral planning.

$54 \quad$ A draft law and by-laws have been developed for setting the framework for the sector strategy development but, as the framework has not been adopted, there is no formal system for sectoral policy planning in place. 
The general framework is in place in Albania, Bosnia and Herzegovina, Kosovo and the former Yugoslav Republic of Macedonia. However, in Bosnia and Herzegovina and the former Yugoslav Republic of Macedonia it concentrates mainly on institutional, and not sectoral, planning. In these two countries, fixed hierarchy and typology of plans are also in place. The quality of planning is fundamentally influenced by the requirements set for the development and content of sectoral plans and the organisation of implementation monitoring. Such requirements are also in place in Albania. However, only Bosnia and Herzegovina has developed a comprehensive monitoring system ${ }^{55}$.

It is easier for the CoG to ensure coherence between the strategies and to conduct quality control if it has the mandate and capacity to direct and guide the development process of the strategic documents (taking into consideration the type and overall number of the planning documents). Most of the new EU member states, while they were in the EU accession process, have struggled with high volumes of strategic documents. They have seen a rapid upward trend in strategy development in the first 5-10 years of the integration process, and have tried to decrease the number of such plans and to ensure better coherence afterwards. The Western Balkans is not exception, and is still experiencing increases in the number of newly-developed sectoral strategy documents, with often modest involvement of the CoG in steering or improving the policy planning system.

Figure 10. Sectoral strategies planned to be adopted in 2015 and 2016

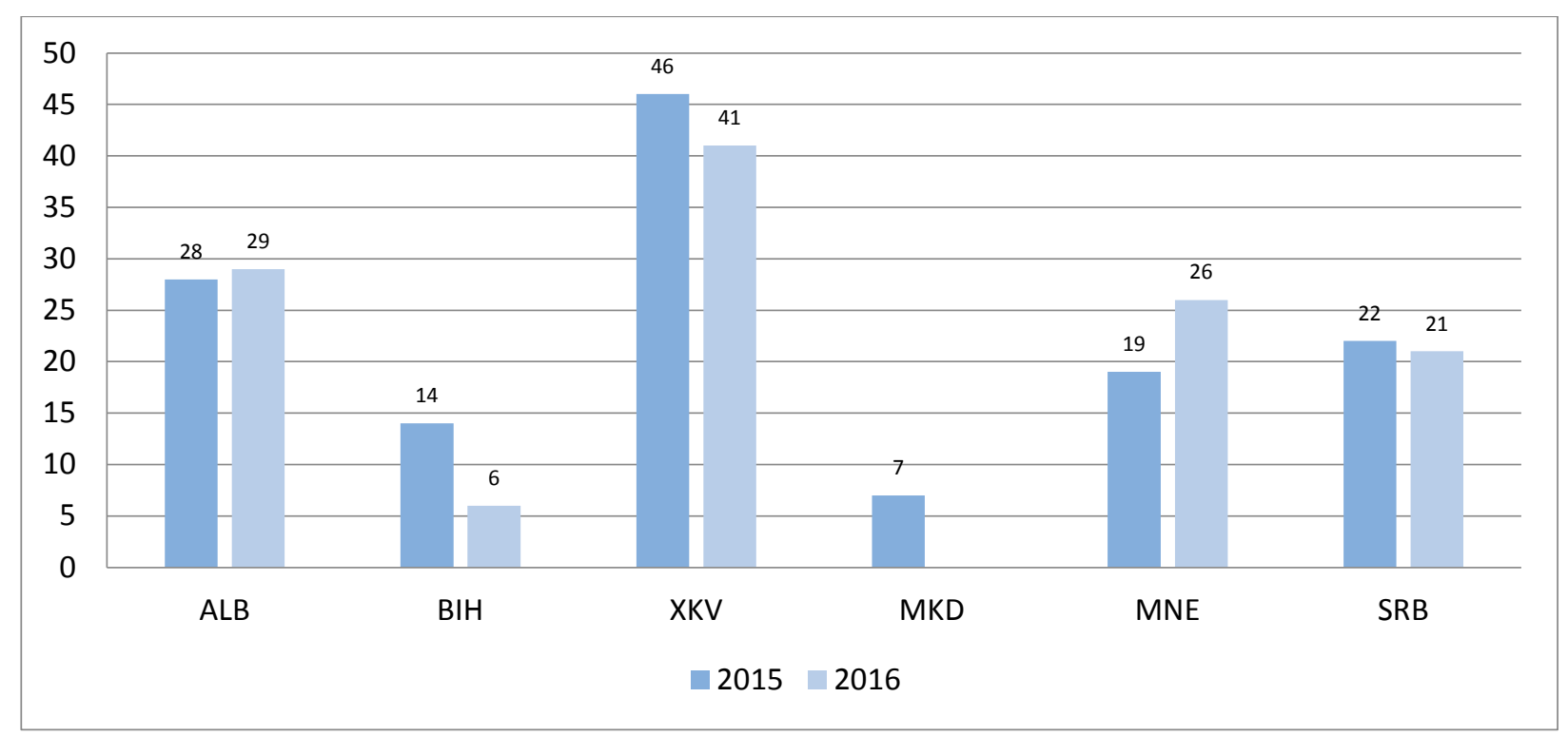

Source: SIGMA (2015), Baseline Measurement Reports, OECD Publishing, Paris. Also documents and data provided by the administrations in June-September 2016.

Most of the governments of the Western Balkans (except Bosnia and Herzegovina, and the former Yugoslav Republic of Macedonia) plan to adopt more than 20 strategies annually, which is obviously a high number, taking into account the capacities of their administrations and the complexity of developing such documents. Kosovo is an exception, in that it has planned to adopt more than 40 strategies both in 2015 and 2016. The statistics of the former Yugoslav Republic of Macedonia are not fully comparable with the other Western Balkan economies for two reasons. First, the former Yugoslav Republic of Macedonia has a well-developed institutional planning system (similar, for example, to Turkey) and as a consequence the government uses fewer sectoral strategies than the other jurisdictions. Second, this specificity of the system has been accompanied by political turmoil, as the long-serving caretaker government is not in a position to prepare long-term policies for adoption. Overall, it can be said that the figures of the Western Balkans illustrate that the CoG does not have sufficient tools and power to help the ministries to consolidate the policies and limit the number of 
developed strategies. This in turn leads to a continuous fragmentation of the sectoral planning system. When analysing the list of strategies planned for adoption in 2015 and 2016, five of the six Western Balkan jurisdictions are planning numerous strategic documents that could be integrated into wider and more comprehensive sectoral policy plans, and not adopted as stand-alone documents. For example:

- Albania is planning to have a separate policy document for Safety and Health at Work and a Strategy for the Prevention and Control of Chronic Diseases (2016-2020), while at the same time also planning to develop and adopt a sectoral Health Strategy $(2015-2020)^{56}$.

- Bosnia and Herzegovina is planning to adopt separate strategies for Human Rights and also for the Fight Against Discrimination, having in addition adopted the Strategy for Preventing and Combating Violence Against Women and Domestic Violence in $2015^{57}$.

- Kosovo is planning to adopt three separate strategic documents in one policy area-the Action Plan for Climate Change, the Action Plan on Air Quality, and the National Emission Reduction Plan. It also plans to have separate strategies on Cultural Heritage and Cultural Development ${ }^{58}$.

- Montenegro is planning to have separate strategies for Reintegration of Persons Returned under Readmission Agreement, for Integrated Management of Migration, and for Improving the Position of Roma and Egyptians. There are also several fragmented strategies in the policy areas of health, education and economic development ${ }^{59}$.

- Serbia is planning to have parallel strategies on Public Health and Rare Diseases. It also plans to have a separate strategy in the narrow policy field of hunting.

These are illustrative examples of the fragmentation that is recurrent in sectoral planning in most of the policy areas in the Western Balkans. It is also reflected in their levels of backlog.

Figure 11. Implementation backlog of sectoral strategies in 2014 and 2015 in the Western Balkans

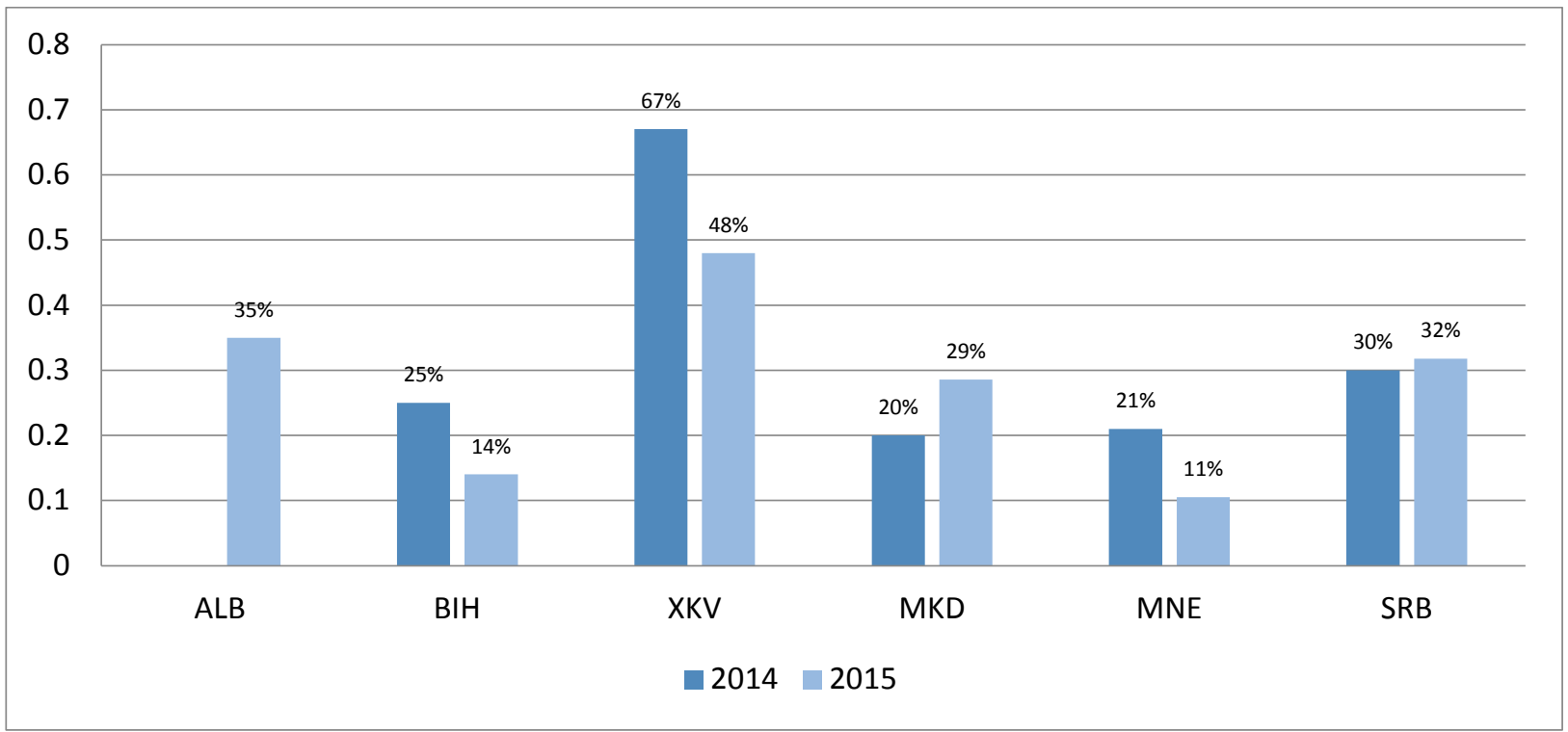

Source: SIGMA (2015), Baseline Measurement Reports, OECD Publishing, Paris. Also documents and data provided by the administrations in June-September 2016.

Analysis of the National Plan for European Integration 2016-2020, Albania.

Analysis of the Government Work Plan 2016, Bosnia and Herzegovina.

Analysis of the Annex to the Government Annual Work Plan 2016, Kosovo.

Analysis of the Work Plan of the Government 2016, Montenegro. 
Bosnia and Herzegovina, Montenegro and Kosovo have managed to decrease the backlog of sectoral strategy development in 2015 compared to 2014. In Serbia, the backlog has slightly increased, as is the case in the former Yugoslav Republic of Macedonia, where the political situation has an impact on the statistics. In Kosovo, there is a clear correlation between the high number of planned strategies and the high backlog, illustrating the weak role of the CoG in steering the sectoral planning system and a clear need for change ${ }^{60}$. In Albania, it is challenging to calculate the backlog, and this was not done for 2014, as planning for sectoral strategy development is disordered and has not been managed through central planning documents. Sectoral strategy development has traditionally been linked to the elaboration of the National Strategy for Development and Integration (NSDI). However, due to extensive delays in developing the NSDI for the new period, there was no operational planning for strategy development in the period of 2012-2015. Currently, development of new sectoral strategies is planned in both the NSDI and the National Plan for European Integration, however without ensuring coherence between these two documents ${ }^{61}$.

Another crucial issue is the financial affordability of the policies spelled out in sector strategies. A basic requirement for ensuring financial affordability is that the sector strategies include complete financial estimates on the implementation of planned measures. This is also a precondition for programming the costs into medium-term budgetary frameworks. Again, the key CoG body, in close co-operation with the MoF, has a central role in setting the formal requirements for financial estimates (costing) of the sectoral strategies and conducting quality control during development, in particular before the strategies are adopted by the government.

Figure 12. Completeness of financial estimates in sector strategies ${ }^{62}$

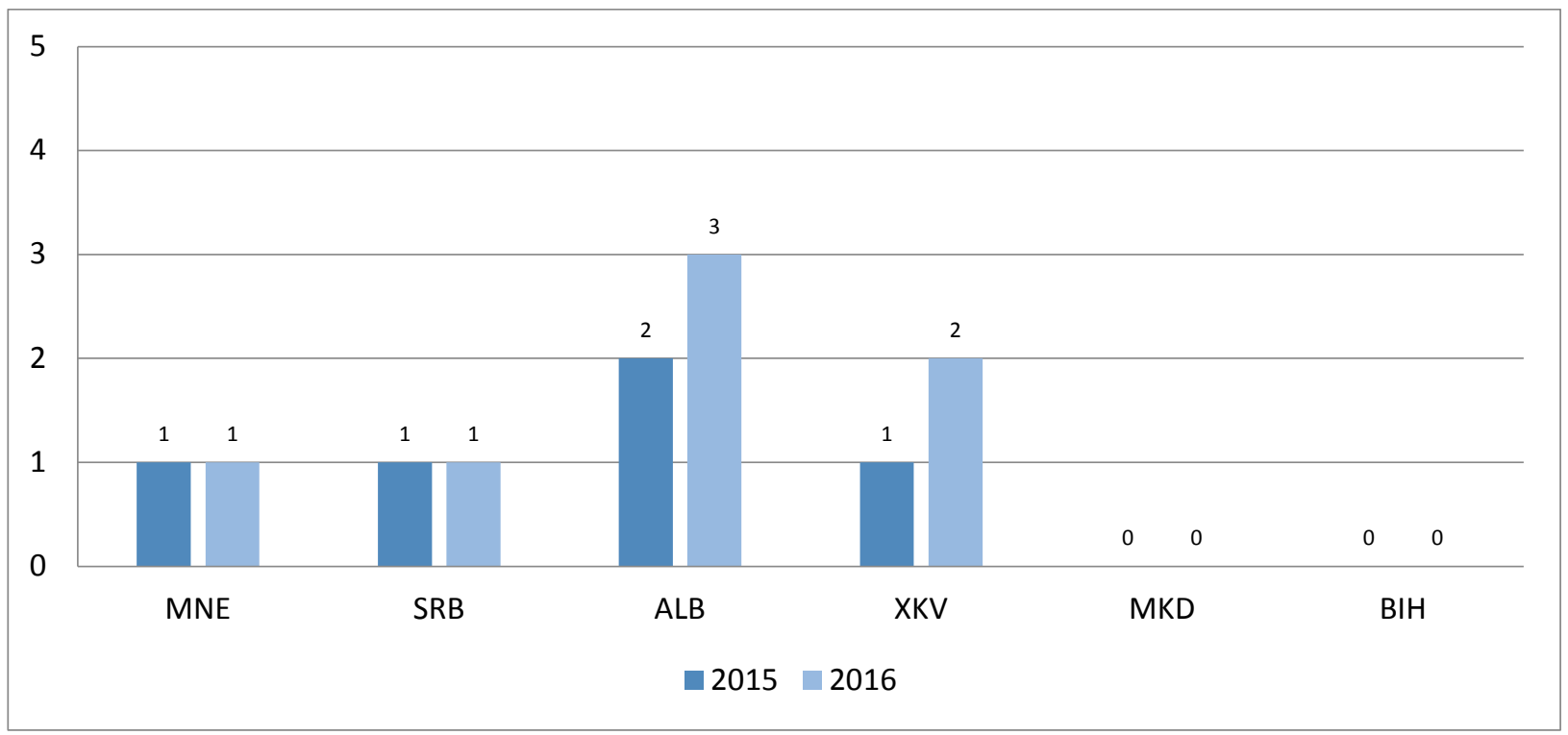

Source: SIGMA (2015), Baseline Measurement Reports, OECD Publishing, Paris. Also documents and data provided by the administrations in June-September 2016.

The level of maturity of the system for costing the strategies is very low in the region as a whole, as has been described by the SIGMA measurement (on a scale from 0 to 5). None of the jurisdictions has

60 For more detailed analysis on Kosovo's strategic planning and corresponding recommendations for change, see SIGMA (2016), Monitoring Report, The Principles of Public Administration, Kosovo, OECD Publishing, Paris, pp. 12-17.

61

Analysis of the National Plan for European Integration 2016-2020 and the National Strategy for Development and Integration 2015-2020, Albania.

62

Methodological Annex to the Indicators, in SIGMA (2015), Baseline Measurement Reports, OECD Publishing, Paris, p. 10.

For 2015, the five latest strategies adopted by the government in 2014 and, for 2016, the five latest strategies adopted by the government in 2015 were analysed for each country. 
detailed, formal requirements in place for preparing financial estimates for the strategies, and they are not consistently prepared and attached to the strategy documents. The main aspect that is regulated in connection with strategies is their link with the medium-term budgetary framework. This is of course important, but it is not sufficient when more detailed requirements have not been set for how to conduct costing and create a link with financial planning in practice. In Bosnia and Herzegovina, detailed costing requirements are not set; in the former Yugoslav Republic of Macedonia it is worth mentioning that, while the requirements for the costing of sector strategies are not set, financial planning at the institutional level is well established. Montenegro and Serbia have general financial calculation requirements in place ${ }^{63}$, but these either cover only some aspects of the costing (e.g., in the case of Serbia, financial estimate requirements are in place in the framework of RIA and for El-related issues) or are not consistently applied (in the case of Montenegro, only two out of the five most-recently adopted strategies include financial estimates). Albania and Kosovo have a more advanced level in preparing financial estimates for strategies, comparatively. In both jurisdictions, some financial estimates are included in most of the recently developed strategies. In Albania, the estimates are more detailed, including systematic information on expenditure needs. In addition to the more advanced level of costing in strategies, Albania and Kosovo are the only two jurisdictions which have improved their performance in this aspect, compared with the 2015 SIGMA Baseline Measurement.

However, in all the Western Balkan economies systematic expenditure information needs to be complemented with clear identification of the sources of financing, including donor assistance, and the preparation of financial estimates should be common, basic practice used for all strategies that the governments adopt. 


\section{Regular monitoring of government performance}

Monitoring is one of the key tools in ensuring that governments are able to achieve their objectives. Therefore, the CoG needs to review progress regularly to measure how the policy objectives, including the outcomes of government work, are achieved. When doing that, the CoG should focus on the central planning documents and ensure the clarity of institutional responsibilities in terms of delivery. The same applies to sectoral strategies, where implementation also needs to be monitored against set objectives.

Enabling public scrutiny is another key aim of monitoring. Without having implementation reports of the plans of the government, neither the parliament nor the wider public are able to assess the performance of the executive. Therefore, annual reports on government performance should be publicly available and open for parliamentary scrutiny.

Figure 13. Extent to which reporting provides information on the outcomes achieved ${ }^{64}$

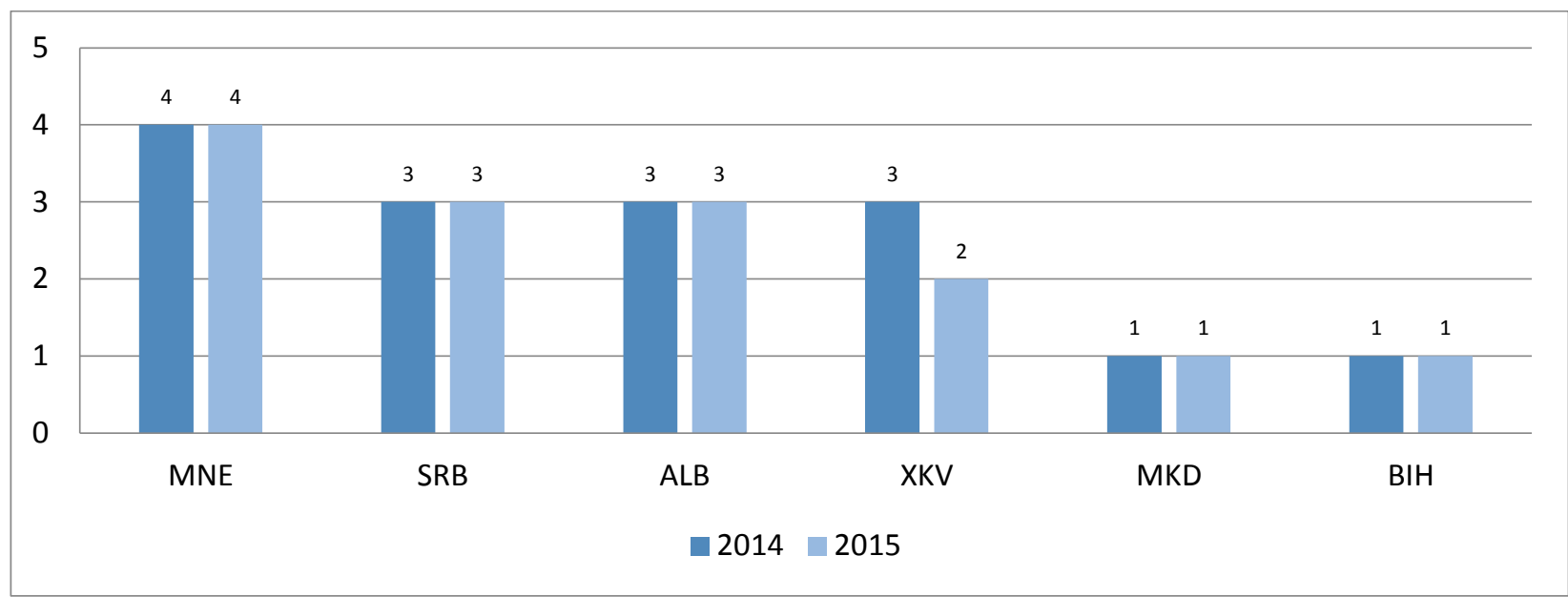

Source: SIGMA (2015), Baseline Measurement Reports, OECD Publishing, Paris. Also documents and data provided by the administrations in June-September 2016.

Since May 2015, there has been no particular progress in monitoring government performance compared with the 2015 Baseline Measurement. Montenegro is a frontrunner, having the most complete monitoring system. Montenegro is also one of the countries with the lowest implementation backlogs, which illustrates that well-organised and transparent monitoring directly contributes to the delivery of plans. The former Yugoslav Republic of Macedonia and Bosnia and Herzegovina have the lowest maturity level of a monitoring system. In the case of the former Yugoslav Republic of Macedonia, this is mainly due to the closed nature of the process, as most of the key components are in place, but few reports are published and/or sent to the Parliament. 
Table 11. Key characteristics of the monitoring systems of the Western Balkans

\begin{tabular}{|c|c|c|c|c|c|c|c|c|c|}
\hline & \multicolumn{4}{|c|}{ Government's Annual Work Plan } & \multicolumn{2}{|c|}{ Any report } & \multirow[b]{2}{*}{$\begin{array}{c}\text { Report } \\
\text { on El } \\
\text { process } \\
\text { exists }\end{array}$} & \multirow[b]{2}{*}{$\begin{array}{c}\text { Reporting } \\
\text { on sectoral } \\
\text { strategies is } \\
\text { functional }\end{array}$} & \multirow[b]{2}{*}{$\begin{array}{c}\text { Budget } \\
\text { report } \\
\text { exists }\end{array}$} \\
\hline & $\begin{array}{l}\text { Quarterly/ } \\
\text { monthly } \\
\text { report }\end{array}$ & $\begin{array}{l}\text { Annual } \\
\text { report }\end{array}$ & Published & $\begin{array}{l}\text { Sent } \\
\text { to } \\
\text { Parlia- } \\
\text { ment }\end{array}$ & $\begin{array}{l}\text { Covers } \\
\text { outputs }\end{array}$ & $\begin{array}{c}\text { Covers } \\
\text { outcomes } \\
\text { and } \\
\text { objectives }\end{array}$ & & & \\
\hline ALB & yes & yes & yes & no & yes & no & yes & no & yes \\
\hline BIH & yes & yes & yes & yes & yes & no & No & no & yes \\
\hline XKV & yes & yes & yes & no & yes & no & yes & no & yes \\
\hline MKD & yes & yes & no & no & yes & no & yes & no & yes \\
\hline MNE & yes & yes & yes & no & yes & yes & yes & no & yes \\
\hline SRB & no & yes & no & no & yes & no & yes & no & yes \\
\hline
\end{tabular}

Source: SIGMA (2015), Baseline Measurement Reports, OECD Publishing, Paris. Also documents and data provided by the administrations in June-September 2016.

A more detailed examination of the characteristics of the monitoring systems of the Western Balkans demonstrates that the key challenge for all the centres of government is to move from a system reporting on basic outputs to monitoring and analysing the outcomes of the government's work. Montenegro has achieved this for its sectoral strategies ${ }^{65}$, and outcome-oriented monitoring is also used in the former Yugoslav Republic of Macedonia when reporting on sector strategies, albeit only randomly. At the same time, most of the Western Balkan governments do not have a functional monitoring system for the sectoral strategies at all, and their jurisdictions only concentrate on outputs when monitoring the implementation of central planning documents.

Many EU and OECD countries have programmed monitoring against objectives into budget reports, but several countries also monitor government performance, either within the framework of regular Government Programme reports, through separate performance reviews, or through comprehensive reports measuring progress against the objectives the government set when entering into office. In order to ensure that the latter approach functions properly, clear objectives need to be set in the planning documents at the outset. Not setting clear objectives, with measureable outcome-level indicators and targets at the planning phase, is one of the factors that hinder the Western Balkan economies in their efforts to move towards an outcome-based monitoring and reporting system.

As examples of good EU Member State practices:

- At the regional level, the Scottish Government ${ }^{66}$ has launched the National Performance Framework. This sets clear objectives and indicators against which progress is monitored and measured $^{67}$;

- The Irish Government publishes an annual Government Performance Report which covers progress on priority objectives and key measures ${ }^{68}$;

65 Even though detailed requirements for strategy development-including monitoring-are not set. Hence, the sustainability of good quality reporting on strategies is not ensured.

66 Scotland is part of the United Kingdom, therefore, the Scottish Government does not have the authority of an independent, state-level government. However, its governance structure corresponds to ordinary governance structures and it can therefore serve as an example to the Western Balkan countries and Kosovo. 
- Both Finland and Estonia use a system of comprehensive annual reports to analyse progress against set objectives. These monitoring reports are also used during the following annual medium-term budget planning and government work planning cycle;

- Slovakia has developed good high-level monitoring where outcome-oriented monitoring of government programmes by the Government Office is complemented by so-called monitoring days, where the Prime Minister, briefed by his/her advisers, visits a ministry and, if necessary, draws up an action plan to allow for better achievement of the set objectives ${ }^{69}$.

Generally, in the majority of the Western Balkan governments, central planning documents do not set measurable objectives for the government. The quality of monitoring clearly reflects the structure and quality of the planning documents. In countries with numerous central planning documents, monitoring is also more fragmented, with several separate reports, often compiled by different units within the CoG. This makes consolidation around key objectives more challenging. 


\section{General conclusions}

The legal frameworks setting the critical functions of the CoG are in place, and routines ensuring the basic functioning of the system are well-established in the Western Balkans. When analysing the structural set-up for fulfilling the nine core functions of the CoG, it can be concluded that the structures for ensuring legal conformity, preparing government sessions, co-ordinating government communication activities, and handling relations with the parliament are situated at the key CoG institutions in all of the Western Balkan governments. The structural units are well-established, with clear mandates and solid staffing, and function as planned. Ensuring policy affordability is managed by the MoFs. El co-ordination is managed either by a separate ministry or a central directorate/secretariat. All are established and generally function acceptably. Co-ordination of the development of government priorities and work programmes, analysis of the policy content of draft policy proposals, and the monitoring of government performance are the most challenging functions in relation to staff allocation, organisational structure and distribution of these tasks between the units and/or institutions within the CoG.

The CoG bodies in the Western Balkan governments are equipped with solid legal frameworks for preparing government decisions in a transparent manner and ensuring legal conformity. The centres of government of Albania, Kosovo and Montenegro use transparent and open models with strong mandates for the CoG to be involved in co-ordinating the policy content of the proposals and to have the authority to return items to their initiators, and not purely on technical grounds. These are also the jurisdictions where the manageable number of items in the government sessions enables the active involvement of the CoG in the decision-making process. The combination of these components helps to ensure that government decisions are of higher quality, are transparent, and are legally correct. Serbia and the former Yugoslav Republic of Macedonia use more closed models, where the role of the CoG is more technical. This more limited role is accompanied by a high volume of agenda items (many of which are only technical/administrative in nature). This further hinders the involvement of the CoG in reviewing the content of the proposals and ensuring their quality. Bosnia and Herzegovina applies a model similar to that of both the former Yugoslav Republic of Macedonia and Serbia, but ensures greater transparency for the public about the decision-making work of the government.

Strategic planning systems in the Western Balkans are fragmented and do not enable the full delivery of government plans. This is partly a consequence of the authority and capacity of the CoG bodies, as most of these bodies have a weaker mandate and less resource for co-ordinating planning when compared to the preparation of government decisions and ensuring legal conformity. Albania and Kosovo link planning with finances, but have cumbersome central planning systems that have several different central planning documents and, in the case of Kosovo, high implementation backlogs. Specific regional challenges include: streamlining the medium-term planning process, in particular ensuring better coherence between medium-term and annual planning, as well as El planning and national planning documents; consolidating sectoral policy-planning systems that are complemented by strengthening the authority and capacity of the CoG to steer the development of sectoral plans; and improving the costing of reforms and linking planning with financing.

The monitoring systems of the Western Balkan governments are broadly in place to ensure regular feedback to the government on the progress of the implementation of activities. However, with the exception of Montenegro, the centres of government are not yet monitor progress against objectives and to measure the outcomes of what the government has achieved. Fragmentation and insufficient frameworks for sectoral policy planning also affect the monitoring of sectoral policies, leading to a situation where in most of the Western Balkan economies there is no overview on how sectoral policies are implemented. 


\section{The SIGMA Programme}

SIGMA (Support for Improvement in Governance and Management) is a joint initiative of the OECD and the EU, principally financed by the EU. SIGMA has been working with countries on strengthening public governance systems and public administration capacities for almost 25 years.

In partnership with the European Commission (EC) Directorate-General for Neighbourhood and Enlargement Negotiations (DG NEAR), we currently work with:

- Albania, Bosnia and Herzegovina, the former Yugoslav Republic of Macedonia, Kosovo, Montenegro, Serbia, and Turkey as EU accession countries

- Algeria, Armenia, Azerbaijan, Egypt, Georgia, Jordan, Lebanon, Moldova, Morocco, Tunisia and Ukraine as EU Neighbourhood countries

SIGMA provides assistance in six key areas:

1. Strategic framework of public administration reform

2. Policy development and co-ordination

3. Public service and human resource management

4. Accountability

5. Service delivery

6. Public financial management, external audit and public procurement

SIGMA reviews and gives feedback on:

- Governance systems and institutions

- Legal frameworks

- Reform strategies and action plans

- Progress in reform implementation

SIGMA provides:

- Advice on the design and prioritisation of reforms

- Methodologies and tools to support implementation

- Recommendations for improving laws and administrative arrangements

- Opportunities to share good practice from a wide range of countries, including regional events

- Policy papers and multi-country comparative studies.

For further information on SIGMA, consult our website:

www.sigmaweb.org

(c) OECD 2017 